\title{
Design of a Metamaterial-Based Foundation for Fuel Storage Tanks and Experimental Evaluation of its Effect on a Pipeline System
}

\author{
Moritz, Wenzel \\ University of Trento, Department of Civ., Env. and Mech. Engineering \\ Via Mesiano 77, 38123 Trento, Italy \\ moritz.wenzel@unitn.it \\ Francesco, Basone \\ University of Enna "Kore" Engineering and Architecture Faculty \\ Cittadella Universitaria, 94100 Enna, Italy \\ francesco.basone@unikore.it \\ Oreste S., Bursi \\ University of Trento, Department of Civ., Env. and Mech. Engineering \\ Via Mesiano 77, 38123 Trento, Italy \\ oreste.bursi@unitn.it
}

\section{ABSTRACT}

The recent advance of seismic metamaterials has led to various concepts for the attenuation of seismic waves, one of them being the locally resonant metamaterial. Based on this concept, the so called Metafoundation has been designed. It can effectively protect a fuel storage tank from ground motions at various fluid levels. In order to show the effectiveness of the proposed design, the response of the Metafoundation is compared to the response of a tank on a traditional concrete foundation. The design process of conceiving the Metafoundation, optimizing it for a specific tank, and its seismic response are described herein. Furthermore, the response of a tank during a seismic event can cause severe damages to pipelines connected to the tank. This phenomenon can be of critical importance for the design of a seismic tank protection system and must be treated with care. Since the coupled structure (tank + foundation + pipeline) exerts highly non-linear behavior, due to the complexity of the piping system, a laboratory experiment has been conducted. More precisely, a hybrid simulation that uses the Metafoundation and a tank as a numerical substructure (NS) and a piping system as a physical 
Journal of Pressure Vessel Technology

substructure (PS) was employed. To make the results relatable to the current state of the art, additional experiments were performed with concave spherical bearing devices (CSBs) as an isolation system in the NS. The Metafoundation offered a clear attenuation of tank stresses and also reduced the stresses in the piping system.

\section{INTRODUCTION}

Natural hazards such as earthquakes can cause significant damages to the environment and the community. Of special interest to many studies on natural hazards are NaTech events (natural technological events) [1-3], which can be caused by the interaction of a seismic incident with the failure of critical technical components. These events include Loss Of Containment (LOC) of fuel storage tanks, pipelines and other components of e.g. petrochemical plants and nuclear power plants. LOC events of such critical infrastructures need to be avoided at the highest priority, as past NaTech disasters have displayed their potential in causing substantial damage to the community and the environment $[4,5]$.

In order to protect structures from seismic effects, various strategies have found application in the field of earthquake engineering. The standard form of seismic isolation uses lead-rubber bearings [6] or spherical bearing devices [7]. This type of seismic protection is able to isolate a structure of interest from the ground motion, and hence, reduce the stresses appearing in the structure induced by seismic waves at a wide range of frequencies. It has been shown by Jadhav and Jangid [8] that these types of Isolation devices can effectively reduce the stresses in fuel storage tanks. In the present work, we investigate a new type of seismic protection based on metamaterial concepts that may offer an alternative to classical isolators in the future. 
Many different types of Metamaterials exist with interesting wave propagation properties for elastic as well as optical waves [9]. Only recently it has been discovered that a particular type of metamaterial, namely phononic crystals, may be feasible to construct at a reasonable size for the isolation of structures against seismic waves. These phononic crystals exhibit so called band gaps that prohibit waves from propagating through the material when their frequency falls within that gap [10]. Several studies tried to harvest this property for the design of a foundation for the seismic isolation of a superstructure, but none have taken the feedback coming from the structure into account [11-15]. In this work a foundation is developed and optimized, based on the aforementioned concept, for the dynamic protection of a fuel storage tank, while considering realistic feedback from a superstructure. The developed system shows promising results for the reduction of the demand on the tank in the frequency and time domain and will be referred to as Metafoundation. Furthermore, this work evaluates the effect that the proposed foundation may have on a connected piping system and compares the system to a system endowed with classical isolators. Due to the high non-linearity of the studied piping system, the evaluation has been carried out under the aid of a hybrid simulation, which can capture the interaction of the coupled system in a realistic manner [16,17]. In particular, the piping system will be constructed in a laboratory as the PS of the system, while the tank and the foundation are modelled as NSs that are coupled to the experimental setup. In summary, the Metafoundation reduces stresses in a tank as a superstructure, while exhibiting a similar demand as a standard isolator on a connected piping system.

\section{MATERIALS}

The Metafoundation consists of two components, namely the structural matrix and the 
internal resonators. Both parts are made of concrete of strength grade $\mathrm{C} 30 / 37$ with material parameters given by Eurocode 2 [18] and are connected to each other with ideal steel springs. Furthermore, a fuel storage tank was chosen as a superstructure for the system and is considered to be made of common welded construction steel with a strength grade of S235. For the laboratory experiments a welded piping system with a strength grade of S355 and a yield strain limit at $0.2 \%$ has been used. Table 1 shows the material parameters for density, elastic modulus, bulk modulus, Poisson ratio, and yield strength, for all components used in the present work. Note that linear elasticity was assumed for all calculations.

Table 1. Material parameters

\begin{tabular}{lccccc} 
Material & $\begin{array}{c}\text { Density } \\
{\left[\mathbf{k g} / \mathbf{m}^{3}\right]}\end{array}$ & $\begin{array}{c}\mathbf{E} \\
{\left[\mathbf{N} / \mathbf{m m}^{2}\right]}\end{array}$ & $\begin{array}{c}\text { Bulk mod } \\
{\left[\mathbf{N} / \mathbf{m m}^{2}\right]}\end{array}$ & $\begin{array}{c}\text { Poisson } \\
{[-]}\end{array}$ & $\begin{array}{c}\text { Strength } \\
{\left[\mathbf{N} / \mathbf{m m}^{2}\right]}\end{array}$ \\
\hline Concrete & 2500 & 30000 & - & 0.2 & 30 \\
C30/37 & & & & & \\
Steel S235 & 7860 & 210000 & - & 0.3 & 235 \\
Liquid & 1000 & - & 2200 & - & - \\
Steel S355 & 7860 & 210000 & - & 0.3 & 355
\end{tabular}

\section{FUEL STORAGE TANK MODELLING}

Fuel storage tanks can be reduced to two fundamental modes, which are the impulsive and the convective mode. More precisely, the impulsive mode represents that part of the liquid that resonates in phase with the tank walls and appears to move mainly in the horizontal direction, while the convective mode embodies the sloshing motion of the liquid and moves mainly in the vertical direction. A simplified procedure for the modelling of storage tanks has been proposed by Malhotra et al. [19], where the tank is reduced to these two main modes under the aid of design coefficients dependent on the height to radius ratio. When applying the equations below to typical fuel storage tanks, it 
can be found that the impulsive frequency is commonly situated between $3-7 \mathrm{~Hz}$, while the convective mode embodies a much lower frequency around $0.3 \mathrm{~Hz}$. However, for the tank under investigation, the impulsive mode takes up a value of $6.84 \mathrm{~Hz}$, while the sloshing mode resonates at $0.338 \mathrm{~Hz}$. Figure 1 (left) displays a sketch of storage tank with $\mathrm{H}$ and $\mathrm{R}$ denominating the height and radius of the tank, respectively. The two S-DoFs that simulate the impulsive and convective modes are denoted with the subscript $i$, and $c$, respectively and can be seen in Figure 1 (right). Here, they are connected to a rigid frame that contains the remaining mass of the tank.

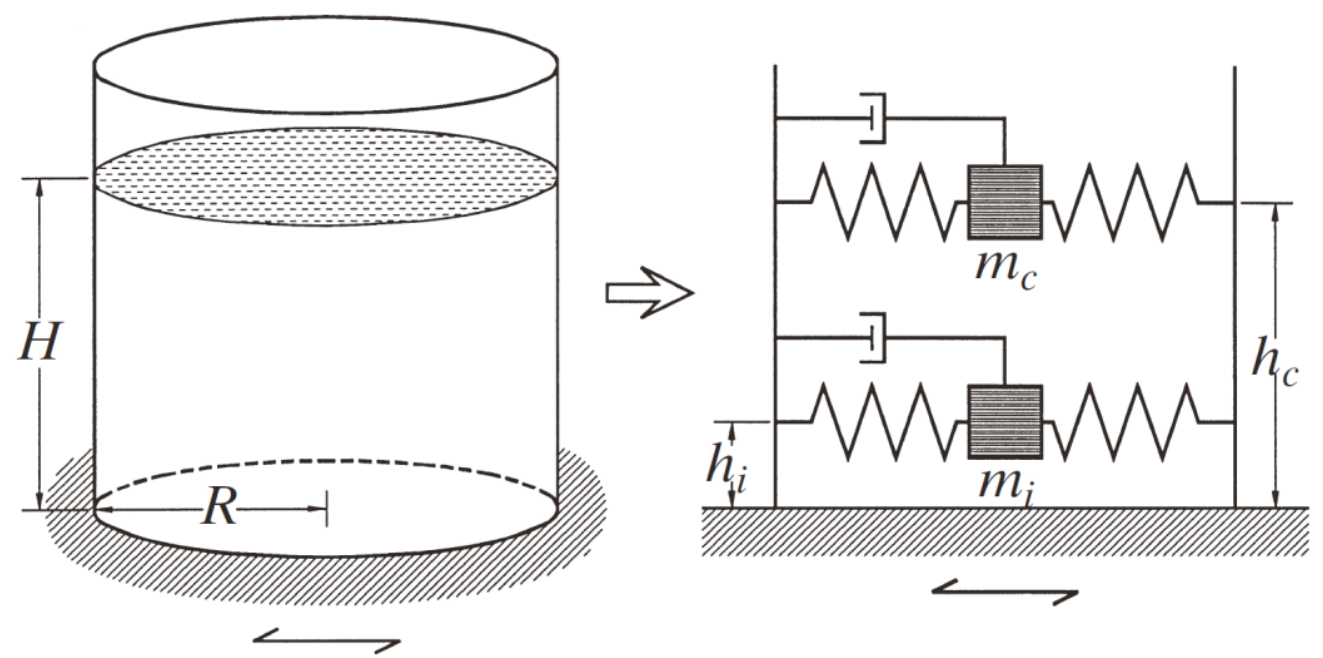

Figure 1. Modelling of a fuel storage tank: (left) Drawing of a generic fuel storage tank; (right) Representation of a fuel storage tank with two SDOFs for the impulsive and convective modes (Figure from [19]).

According to the procedure proposed by Malhotra et al. the vibration periods of the impulsive and convective mode $T_{i}$ and $T_{c}$, and modal masses $m_{i}$ and $m_{c}$ can be calculated with,

$$
\begin{aligned}
& T_{i}=C_{i} H \sqrt{\frac{\rho r}{E t}}, \quad T_{c}=C_{c} \sqrt{r} \\
& m_{i}=\gamma_{i} m_{l}, \quad m_{c}=\gamma_{c} m_{l}
\end{aligned}
$$


here, $i$ and $c$ are describing the impulsive and convective mode, while $\mathrm{E}, \rho$, and $m_{l}$ denote the elastic modulus of the tank wall, the density of the liquid, and the total mass of the liquid, respectively. The parameters $C_{i}$, and $C_{C}$, are empirical parameters while $\gamma_{i}$ and $\gamma_{c}$ are the ratios between the impulsive and convective mass, $m_{i}$ and $m_{c}$, with respect to the total liquid mass $m_{l}$. All of these parameters are given by Malhotra [19] and are dependent on to the slenderness of the tank $H / R$. Note that $t$ is the thickness of the tank wall. Based on these values the stiffness coefficients can be evaluated as,

$$
k_{i}=m_{i}\left(\frac{2 \pi}{T_{i}}\right)^{2}, k_{c}=m_{c}\left(\frac{2 \pi}{T_{c}}\right)^{2}
$$

It has been shown by Belakroum et al. [20] and Maleki et al. [21] how baffles can increase the damping of the convective mode. Due to the possibility of using such baffles against resonance in the convective mode and the fact that the impulsive mode contains the highest participant mass, especially for slender tanks, the Metafoundation has been designed for the attenuation of the impulsive mode solely. Furthermore, a storage tank can experience varying fluid levels, thus, increasing its impulsive frequency with a decrease in fluid height. In order to address this peculiarity, the band gap like properties of a locally resonant metamaterial are exploited. By tuning the lower bound of the band gap to the frequency of the full tank and the upper bound to a frequency a bit higher than the impulsive frequency of a $3 / 4$ filled tank, an attenuation of both frequencies can be achieved. From here onwards, the tank with the full liquid height of $12 \mathrm{~m}$ shall be referred to as STF (Slender Tank Full), while the tank with a liquid height of $9 \mathrm{~m}$ shall be referred to as STnF (Slender Tank not Full). As mentioned in the Introduction section, it is necessary to take the feedback from the superstructure into account. One of the major impacts that this feedback has is the alteration of the modes of the tank. Due to the 
softening of the overall dynamic system for the coupled case, the new eigenfrequency, at which the impulsive mode gets excited most, appears to be smaller than for the tank alone. For all analyses in this work a tank with height $\mathrm{H}$, radius $\mathrm{R}$ and tank wall thickness t of $12 \mathrm{~m}, 4 \mathrm{~m}$, and $6 \mathrm{~mm}$, respectively has been used. Furthermore, Table 2 depicts the various impulsive frequencies caused by the STF and STnF setups in combination with and without the Metafoundation. Here, the Metafoundation, was considered without the resonators, as they will be tuned to the frequency resulting from this modal analysis. Note that the impulsive frequency is where the impulsive mode of the tank shows the strongest response, which depends on the liquid height and the coupled foundation system. Based on these results a band gap with a lower bound of $1.1 \mathrm{~Hz}$ is desired, while the upper bound was found at $2.2 \mathrm{~Hz}$ for the proposed design.

Table 2. First impulsive eigenfrequencies of tank-foundation systems with various liquid levels

\begin{tabular}{lccc}
$\begin{array}{l}\text { Foundation } \\
\text { typology }\end{array}$ & Tank type & Liquid height [m] & $\begin{array}{c}\text { Impulsive frequency } \\
{[\mathbf{H z}]}\end{array}$ \\
\hline \multirow{2}{*}{ Traditional } & STF & 12 & 6.84 \\
& STnF & 9 & 10.05 \\
\hline \multirow{2}{*}{ Meta-foundation } & STF & 12 & 1.26 \\
& STnF & 9 & 1.48
\end{tabular}




\section{DESCRIPTION OF THE STRUCTURE AND DYNAMIC SYSTEM}

The foundation consist of slabs that differentiate the layers, while columns provide the vertical stability. Between the slabs, resonators will be attached to the columns via steel springs and are assumed to slide on a friction less surface, see Figure 2. These layers are perfectly equivalent and can be regarded as the unit cells of the foundation, which can be repeated in the vertical direction. Furthermore, a tank shall serve as a superstructure to evaluate the wave attenuation performance.

Side view

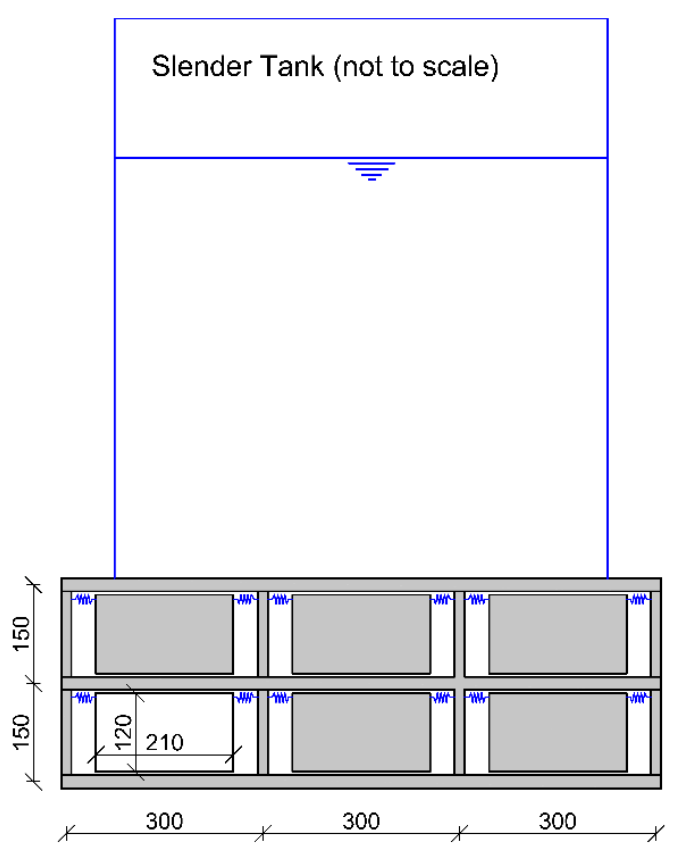

Layout of 1 Layer

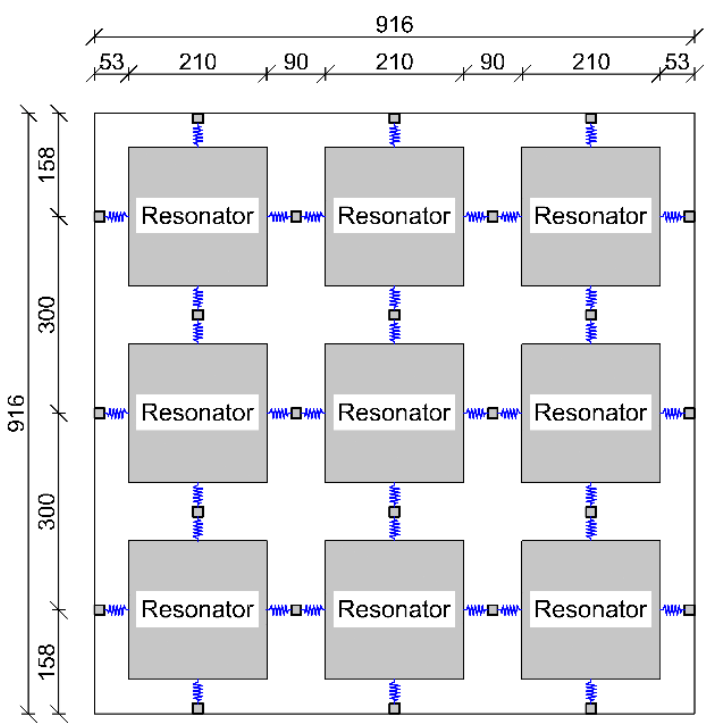

Figure 2. Drawings of the structure: (left) Side view of tank and Metafoundation; (right) Layout of one layer (dimensions in $\mathrm{cm}$ ).

The dimensions of the components on the other hand, were chosen with common values for engineering practices. More precisely, a cross section of $15 \times 15 \mathrm{~cm}$ was used for the columns, which are being spaced apart $3 \mathrm{~m}$ in a square grid. The slabs on the other hand were fixed to $20 \mathrm{~cm}$ thickness and $150 \mathrm{~cm}$ of vertical spacing, while the resonators 
consist of cuboids that are $210 \times 210 \mathrm{~cm}$ wide and $120 \mathrm{~cm}$ high. For the exact geometry see Figure 3.
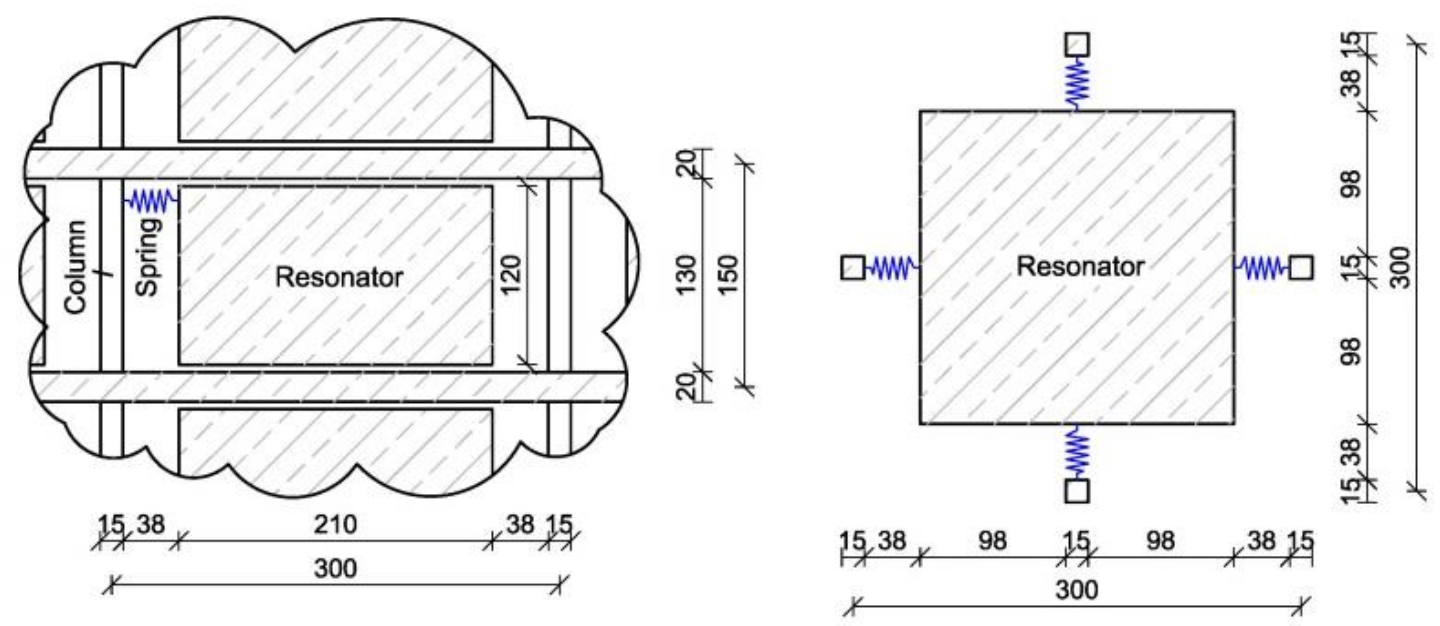

Figure 3. Geometry of the unit cell as part of the concrete matrix; (left) cross section of the foundation; (right) layout of one unit cell (dimensions in $\mathrm{cm}$ )

\section{ANALYTICAL MODEL AND FLOQUET-BLOCH THEOREM}

When assuming that the horizontal displacement is governed by the flexibility of the columns, while the slabs move as rigid bodies, the system can be simplified to a 1D model that propagates only shear type waves in the vertical direction (Figure 4). This entails that the total shear stiffness of one layer can be calculated with the combined horizontal stiffness of all 24 columns. Furthermore, in this model the layers can be regarded as the unit cells of the system and be repeated periodically in the vertical direction. 


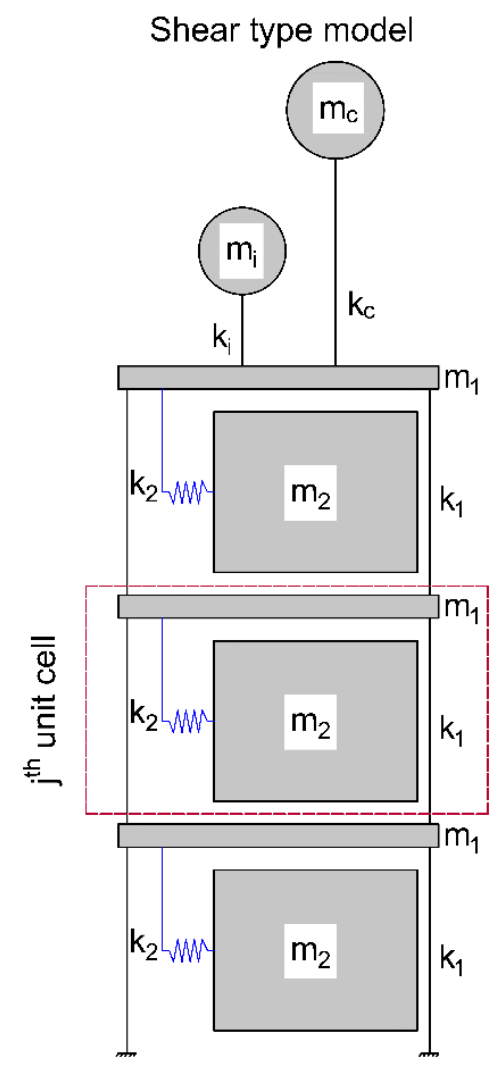

Figure 4. Dynamic system.

Band gaps can be found in periodic structures under the aid of the Floquet-Bloch theorem [22]. These gaps represent frequency regions where elastic waves cannot propagate through the material, and therefore, shall be used to attenuate the response of a superstructure that exerts a varying eigenfrequency. In order to estimate the behavior of the system, the complete coupled structure will be analyzed on its wave propagation behavior. More precisely, frequency and time domain analyses will be carried out on the system, with and without tank, and compared with the dispersion relation of a single unit cell. For these analyses it is necessary to formulate the equations of motion in a general form, so that the unit cell can be repeated in the vertical direction. This can be achieved by formulating the equations for the $\mathrm{j}^{\text {th }}$ unit cell as, 


$$
\begin{aligned}
& m_{1}^{j} \frac{d^{2} u_{1}^{j}}{d t^{2}}-k_{1} u_{1}^{j-1}+2 k_{1} u_{1}^{j}+k_{2} u_{1}^{j}-k_{2} u_{2}^{j}-k_{1} u_{1}^{j+1}=0 \\
& m_{2}^{j} \frac{d^{2} u_{2}^{j}}{d t^{2}}-k_{2} u_{1}^{j}+k_{2} u_{2}^{j}=0
\end{aligned}
$$

here, the mass of the columns is lumped to the slabs and the combined mass is denoted with $m_{1}$; the mass of the resonators (9 per layer) is described with $m_{2} ; 24$ columns per layer provide the equivalent horizontal stiffness for one cell, which is denoted with $k_{1}$; the stiffness of the steel springs that provides the resonators with their resonance frequency is denoted with $k_{2}$; while the horizontal displacement is described with $u$. Since the $\mathrm{j}^{\text {th }}$ unit cell is connected to the previous $j-I^{\text {th }}$ and subsequent $j+l^{\text {th }}$ unit cell, it is necessary to include the displacements of these cells in the equations. This is taken into account by the superscript $(j-1, j, j+1)$ for $\mathrm{u}$, while the subscript $(1,2)$ determines the corresponding mass. In principal, these equations are sufficient for analyzing the uncoupled structure. However, since the coupled response of the system is also of interest, the tank will be modeled with 2 DoFs according to the Malhotra procedure and attached to the top layer of the foundation.

In order to find the metamaterial like properties of the unit cell under study, it is necessary to extend the system to an infinite stack of unit cells. According to the FloquetBloch theorem, the study of an infinite lattice of cells can be reduced to the study of a single cell with Floquet-Bloch quasi periodicity conditions. In line with this, $\boldsymbol{u}(\boldsymbol{x}, t)$ can be expressed as,

$$
\boldsymbol{u}(\boldsymbol{x}, t)=\boldsymbol{u}_{\boldsymbol{k}} e^{i(\boldsymbol{q} \cdot \boldsymbol{x}-\omega t)}
$$


where the frequency is represented by $\omega$, while $\boldsymbol{q}=\left[q_{x}, q_{y}, q_{z}\right]^{T}$ denotes the wave vector in (6). As a consequence,

$$
\boldsymbol{u}(\boldsymbol{x}+\boldsymbol{R})=\boldsymbol{u}(\boldsymbol{x}) e^{i \boldsymbol{q} \cdot \boldsymbol{R}}
$$

with $\boldsymbol{R}$ being the lattice vector. Furthermore, the eigenvalue problem for a dynamic system can be formulated as:

$$
\left(\boldsymbol{K}-\omega^{2} \boldsymbol{M}\right) \boldsymbol{u}=0
$$

here, mass and stiffness matrix are denoted by $\boldsymbol{K}$ and $\boldsymbol{M}$. In order to achieve the dispersion relation, it is necessary to apply the boundary condition (7) to equations (4) and (5), and successively solve the eigenvalue problem as described in (8). When searching for non-trivial solutions for this problem, the dispersion relation can be found as,

$$
\begin{aligned}
& m_{1} m_{2} \omega^{4}- \\
& {\left[\left(m_{1}+m_{2}\right) k_{2}+2 m_{2} k_{1}(1-\cos (q))\right] \omega^{2}+2 k_{1} k_{2}(1-\cos (q))=0}
\end{aligned}
$$

where the dimensionless wave number is denoted with $q$, while $\omega$ describes the circular frequency. Another research group has found a similar solution for an acoustic metamaterial when investigating the negative effective mass phenomenon [23].

\section{RESULTS FOR THE UNCOUPLED FOUNDATION}

The configuration depicted in Figure 2 and Figure 3 resulted in values for $m_{1}, m_{2}$, and $k_{1}$, of $4838 \mathrm{~kg}, 13230 \mathrm{~kg}$, and $7.5 \mathrm{e} 6 \mathrm{~N} / \mathrm{m}$, respectively. Note that these values are given by the geometric design of the foundation, thus leaving only $k_{2}$, the stiffness of the steel springs, for tuning the system. When considering the foundation as a metamaterial, the 
Journal of Pressure Vessel Technology

layers of resonators and slabs become the unit cells. This arrangement has the capability of attenuating elastic waves, if its parameters are chosen correctly. To evaluate this effect, the transmission of an imposed signal will be measured in the frequency domain and the results will be compared to the dispersion relation of the unit cell. For a slender fuel storage tank, a band-gap with a lower bound of approximately $1.1 \mathrm{~Hz}$ was chosen resulting in $k_{2}$ equal to $6.22 \mathrm{e} 6 \mathrm{~N} / \mathrm{m}$ and an upper bound for the band gap of $2.2 \mathrm{~Hz}$. After establishing the geometry and fixing the parameters of the system, the following analyses were carried out on the foundation and the unit cell: (i) A frequency response analysis of a foundation with 1, 5, and 25 layers without damping (Figure 5); (ii) The dispersion relation of the unit cell as part of an infinite lattice (Figure 6). Furthermore, the frequency response analysis was carried out by imposing a base excitation of $\ddot{u}_{\mathrm{in}}=1 \mathrm{~m} / \mathrm{s}^{2}$ at the bottom of the foundation and measuring the output acceleration $\ddot{u}_{\text {out }}$ at the top of the foundation. For a linear elastic undamped system, this can be achieved by writing the equations of motion,

$$
\boldsymbol{M} \ddot{\boldsymbol{u}}(t)+\boldsymbol{K} \boldsymbol{u}(t)=\boldsymbol{F}(t)
$$

and transforming them into the frequency domain with, $\boldsymbol{u}(t)=\boldsymbol{u}_{f}(\omega) e^{i \omega t}, \ddot{\boldsymbol{u}}(t)=$ $-\omega^{2} \boldsymbol{u}_{f}(\omega) e^{i \omega t}$, and $\boldsymbol{F}(t)=\boldsymbol{M I} u_{i n} e^{i \omega t}$ (with $\boldsymbol{I}$ being the identity vector). After dividing by $e^{i \omega t}$ and rearranging the terms we obtain,

$$
\boldsymbol{u}_{f}(\omega)=\left(-\omega^{2} \boldsymbol{M}+\boldsymbol{K}\right)^{-1} \boldsymbol{M} \boldsymbol{I} u_{i n}
$$

Where $\boldsymbol{u}_{f}(\omega)$ describes the vector containing the response amplitude functions in the frequency domain for the individual DOFs, while $u_{\text {in }}$ is the ground acceleration, which was set to a constant amplitude of $1 \mathrm{~m} / \mathrm{s}^{2}$. Furthermore, $\omega$ is the circular frequency of the excitation and the response and is converted to $\mathrm{Hz}$ for Figure 5 and Figure 6. 
Journal of Pressure Vessel Technology

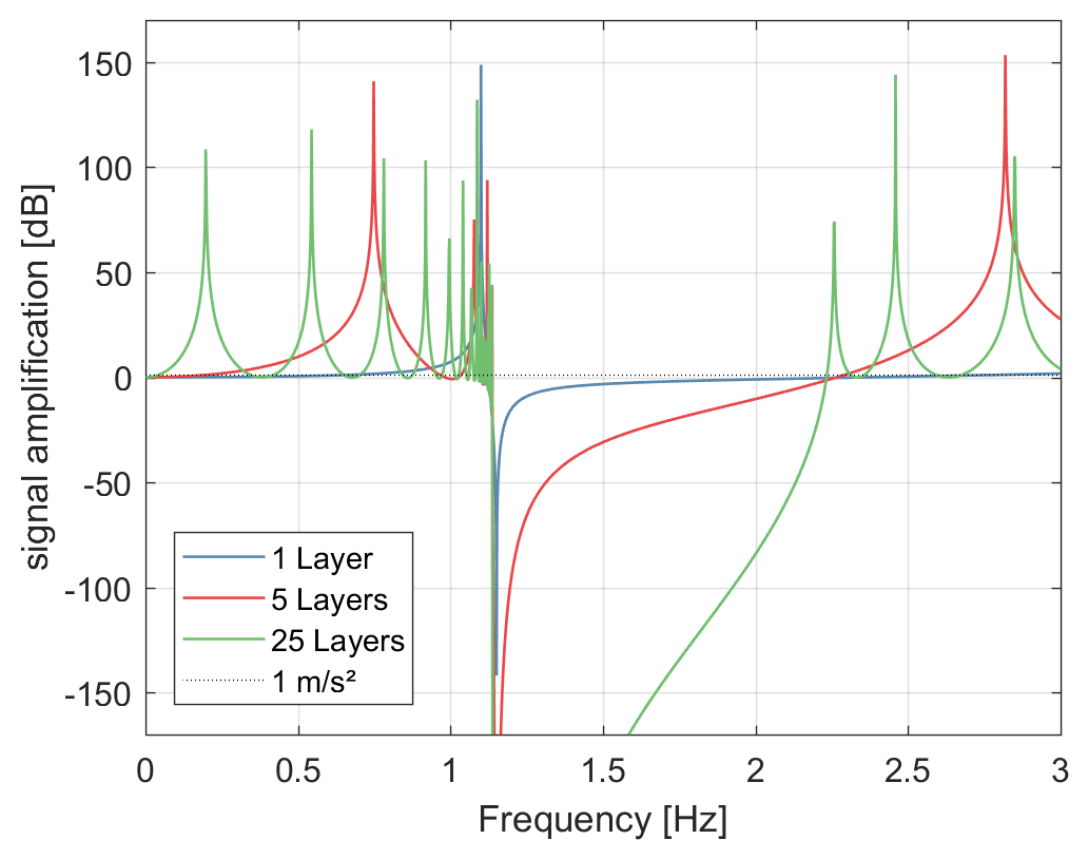

Figure 5. Frequency response function for a foundation with 1, 5, and 25 layers without damping.

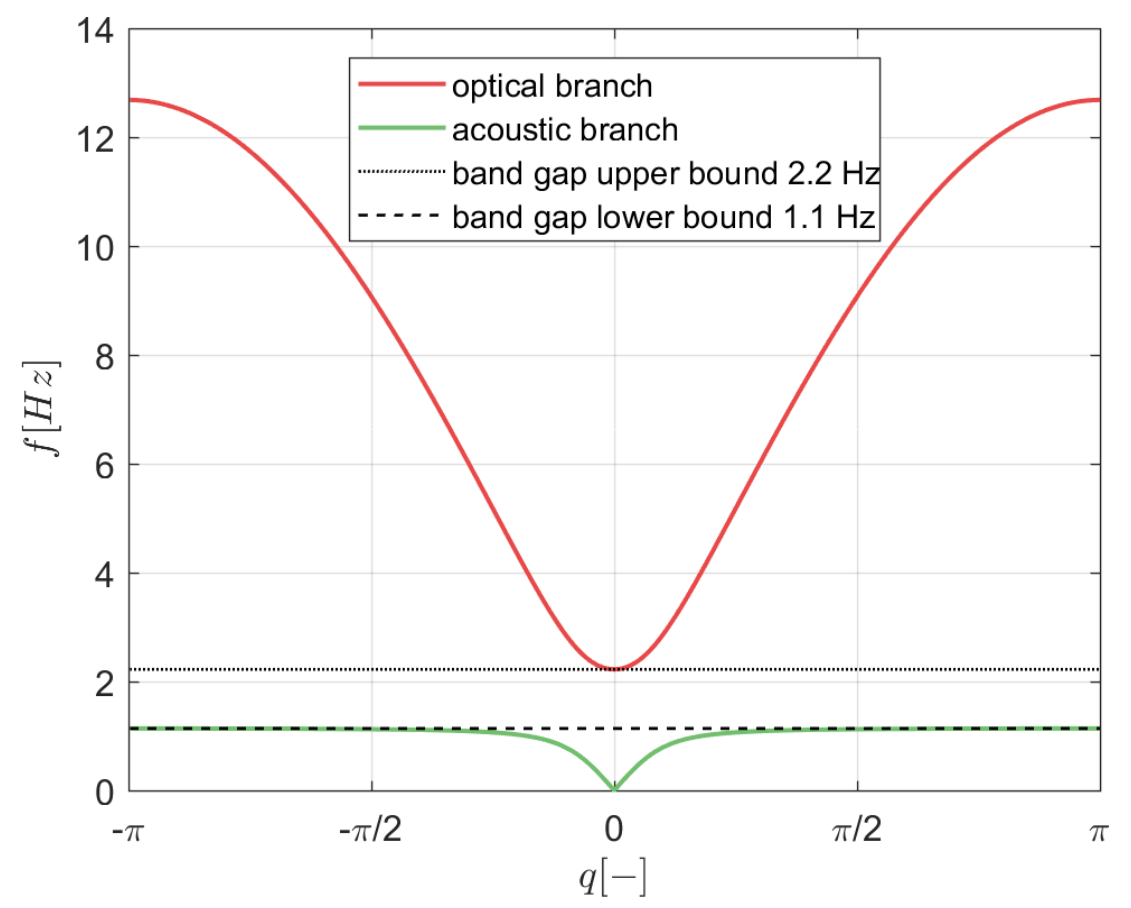

Figure 6. Dispersion relation of the unit cell

Figure 5 displays the signal amplification in $\mathrm{dB}$, where the output acceleration is compared to the input acceleration with $\left(20 * \log \left(\ddot{u}_{\text {out }} / \ddot{u}_{\text {in }}\right)\right)$. When observing Figure 5, a clear attenuation zone becomes apparent between $1.1 \mathrm{~Hz}$ and $2.2 \mathrm{~Hz}$. Here the signal 
amplification drops to the negative $\mathrm{dB}$ regime, resulting in a decreased output at the top of the foundation. The dispersion relation depicted in Figure 6 yields a band gap between 1.1 Hz and $2.2 \mathrm{~Hz}$, which is in line with the predicted attenuation zone of Figure 5. Note that the dispersion diagram maps the frequency of a wave traveling through a system to the resulting wavelength in that system. If no frequency-wavelength pair can be found, a wave at this frequency cannot propagate unhindered. Therefore, in the range from $1.1 \mathrm{~Hz}$ to $2.2 \mathrm{~Hz}$, where there are no solutions for the dispersion equation, the system is expected to attenuate waves. For a more exhaustive explanation of this property see [22]. These results imply that, indeed, an attenuation zone is present in the foundation when regarded as an uncoupled system. However, in order to make a judgement on the viability of this concept, it is necessary to conduct analyses on the coupled system, as discussed in the following chapters.

\section{FREQUENCY RESPONSE ANALYSIS FOR THE COUPLED SYSTEM}

To evaluate the performance of the Metafoundation, two different types of analyses were carried out on the coupled system (tank clamped to the Metafoundation) as well as on the tank clamped to a concrete plate. 

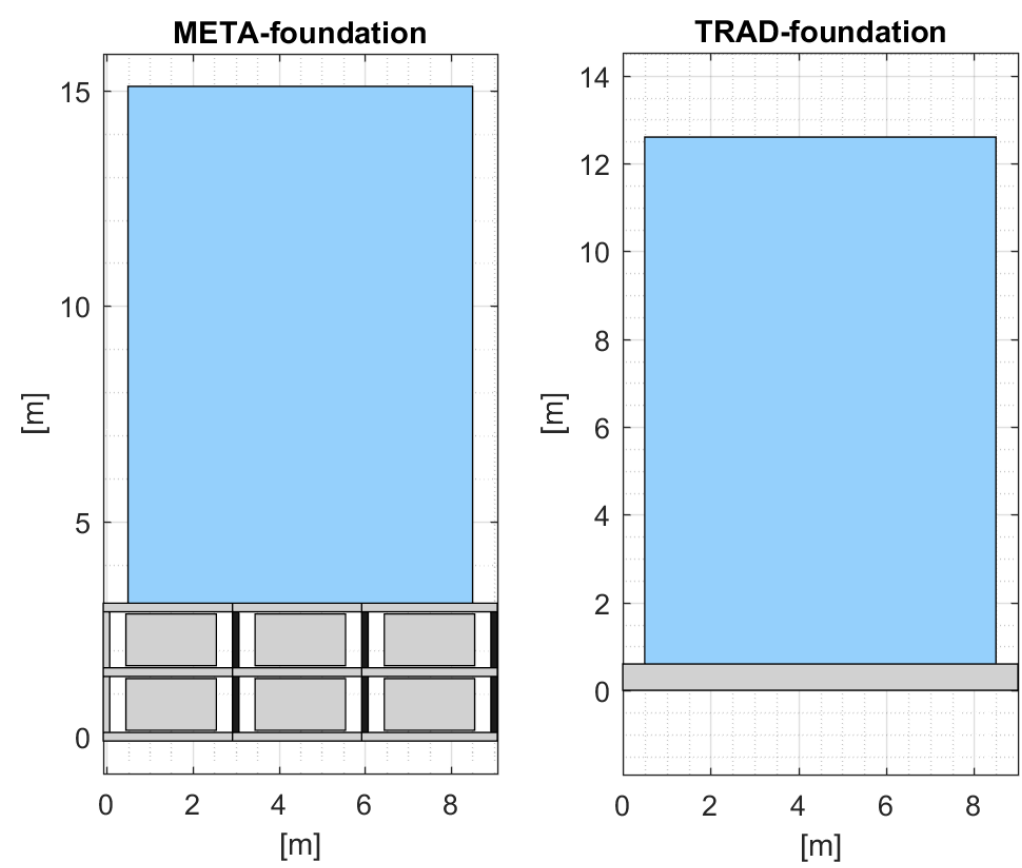

Figure 7. Geometrical characteristics: (left) slender tank including the Metafoundation META; (right) slender tank on a traditional foundation TRAD (dimensions in $\mathrm{m}$ )

In particular, a frequency response analysis showed the performance of the structure for an harmonic excitation, while a time history analysis gave insight in the performance for realistic seismic events. Note that for all analysis form here on forth a Rayleigh damping model of $5 \%$ between $1 \mathrm{~Hz}$ and $5 \mathrm{~Hz}$ has been used. The system, designed for a slender tank with a diameter of $8 \mathrm{~m}$ and $12 \mathrm{~m}$ height, comprises 2 layers with 9 unit cells each.

This system can have varying fluid levels, and therefore, was studied for the STF and the STnF case. The relevant parameters, $m_{1}, m_{2}, k_{1}$, and $k_{2}$ for the foundation and $m_{i}, m_{c}$, $k_{i}$, and $k_{c}$ for the impulsive and convective modes of the tank, are represented in Table 3.

Table 3. Parameter values for the analysis of two tank-foundation systems with various fluid levels.

\begin{tabular}{|c|c|c|c|c|c|c|c|c|}
\hline $\begin{array}{l}\text { Syste } \\
\text { m } \\
\quad[-]\end{array}$ & $\begin{array}{c}\mathbf{m}_{1} \\
{[\mathrm{~kg}]}\end{array}$ & $\begin{array}{c}\mathbf{m}_{2} \\
{[\mathbf{k g}]}\end{array}$ & $\begin{array}{c}\mathbf{k}_{1} \\
{[\mathbf{N} / \mathbf{m}]}\end{array}$ & $\begin{array}{c}\mathbf{k}_{2} \\
{[\mathbf{N} / \mathbf{m}]}\end{array}$ & $\underset{[\mathbf{k g}]}{\mathbf{m}_{\mathbf{i}}}$ & $\begin{array}{c}\mathbf{m}_{\mathbf{c}} \\
{[\mathbf{k g}]}\end{array}$ & $\begin{array}{c}\mathbf{k}_{\mathbf{i}} \\
{[\mathbf{N} / \mathbf{m}]}\end{array}$ & $\begin{array}{c}\mathbf{k}_{\mathbf{c}} \\
{[\mathbf{N} / \mathbf{m}]}\end{array}$ \\
\hline$\overline{\text { STF }}$ & $4.35 \mathrm{E}+4$ & $1.19 \mathrm{E}+5$ & $6.75 \mathrm{E}+7$ & $6.22 \mathrm{E}+6$ & $4.52 \mathrm{E}+5$ & $8.58 \mathrm{E}+4$ & $8.35 \mathrm{E}+8$ & $3.86 \mathrm{E}+5$ \\
\hline $\mathrm{STnF}$ & $4.35 \mathrm{E}+4$ & $1.19 \mathrm{E}+5$ & $6.75 \mathrm{E}+7$ & $6.22 \mathrm{E}+6$ & $3.16 \mathrm{E}+5$ & $8.69 \mathrm{E}+4$ & $1.26 \mathrm{E}+9$ & $3.92 \mathrm{E}+5$ \\
\hline
\end{tabular}


Figure 7 shows the configuration of the slender-tank-foundation system with the full liquid height (META) and the reference system of a tank with a solid concrete slab as a foundation (TRAD). Furthermore, Figure 8 and Figure 9 show the frequency response functions of the impulsive mode for the STF and STnF case, respectively.
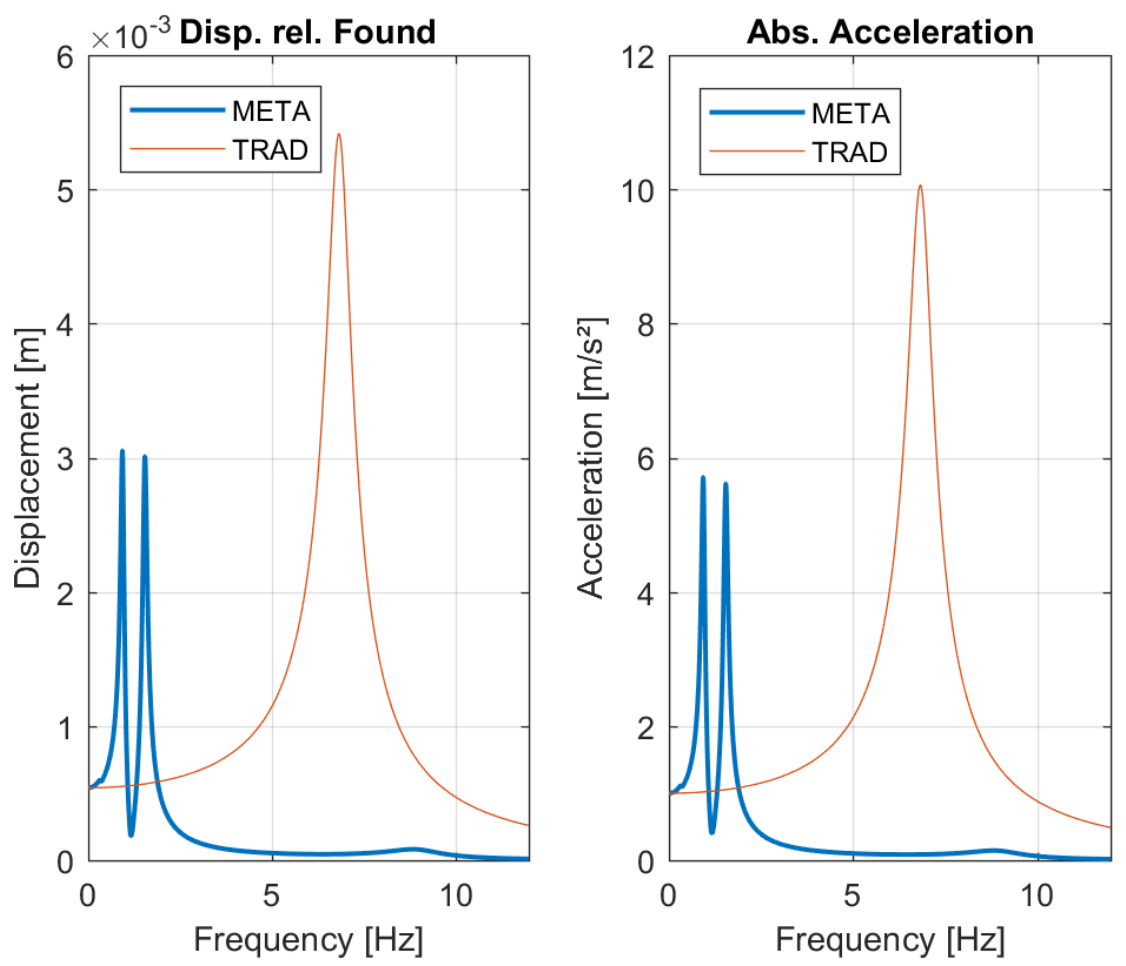

Figure 8. Frequency response function of the impulsive mode of a Slender tank with full liquid height (STF); (left) displacement of impulsive mass compared to foundation; (right) Absolute acceleration of the impulsive mass

The graphs depict the displacement response of the impulsive mode relative to its foundation and the absolute acceleration response of the impulsive mode. Clearly, the STF shows the most effective attenuation with respect to the traditional foundation, while the STnF performs a little less efficient. However, it is worth noting that in terms of magnitude of response the STnF still performs on a similar level as the STF does. Furthermore, the frequency of the resonator has been tuned to produce a lower bound of 
1.1 Hz for the band gap, which also corresponds to the optimal tuning of the two spikes of the frequency response (see Figure 8 META curve). These results were expected, since firstly, the attenuation zone for a finite foundation has different levels of effectiveness in its frequency range, and secondly, a tank with a reduced fluid level experiences less demand due to the reduced mass.
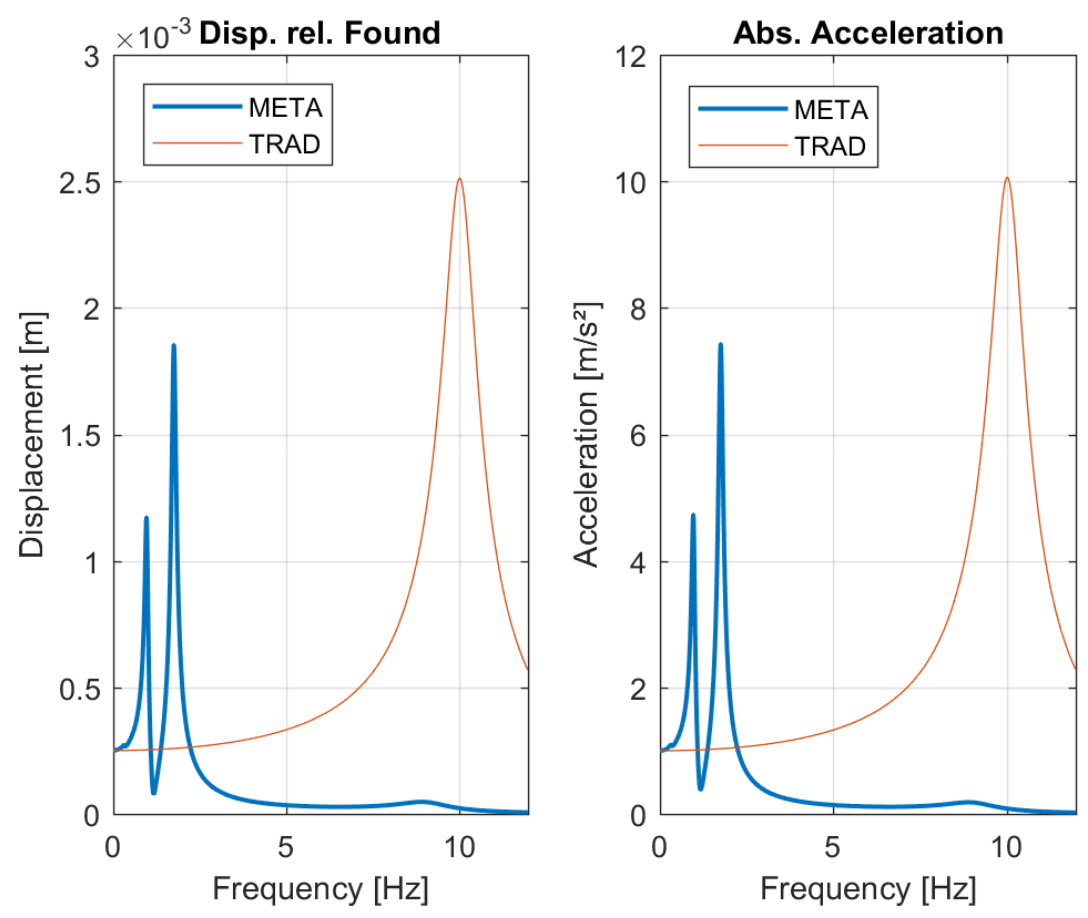

Figure 9. Frequency response of a slender tank foundation system for a reduced fluid level of $3 / 4$ fill (STnF); (left) displacement of impulsive mass compared to foundation; (right) Absolute acceleration of the impulsive mass

\section{SEISMIC RESPONSE ANALYSIS FOR THE COUPLED SYSTEM}

For the assessment of the functionality of the structure, it is not sufficient to consider only calculations in the frequency domain. Therefore, additional analyses were carried out in the time domain for various earthquakes (Table 4) extracted from the European StrongMotion Database (ESM). Here, $\mathrm{R}_{\mathrm{jb}}$ is the epicentral distance, while PGA represents the peak ground acceleration of that record. 
Journal of Pressure Vessel Technology

Table 4. Set of EC 8 compatible ground motions for the site Priolo Gargallo (soil type B) with a return period of 2475 years

\begin{tabular}{lcccc} 
Event (component) & Event ID & Magni. & $\mathbf{R}_{\mathbf{j b}}$ [km] & PGA [m/s' \\
\hline \hline Erincan (X) & 000535 & 6.6 & 13 & 3.81 \\
South Iceland (X) & 006263 & 6.5 & 7 & 6.23 \\
South Iceland Aftersh. (Y) & 006334 & 6.4 & 11 & 7.07 \\
L'Aquila Mainshock (X) & IT0789 & 6.3 & 5 & 4.34 \\
L'Aquila Mainshock (X) & IT0790 & 6.3 & 4 & 4.79 \\
L'Aquila Mainshock (X) & IT0792 & 6.3 & 5 & 5.35
\end{tabular}

Note that the set of seismic records is compatible for a site in Priolo Gargallo in Sicily, Italy with soil type B and a return period of 2475 years (according to Eurocode 8 [24]). For the time integration we employed a classical Newmark-beta scheme with a time step of $0.001 \mathrm{sec}$ and values for $\beta$ and $\gamma$ of 0.25 and 0.5 , respectively. Figure 9 and Figure 10 present the response of the system for an earthquake that occurred in South Iceland on the $21^{\text {st }}$ of June 2000 with a magnitude of 6.4 and a PGA of $7.07 \mathrm{~m} / \mathrm{s}^{2}$. In order to judge the results of the time history simulations, the base shear and overturning moment of the tank were considered as governing for the limit state. More precisely, Figure 9 depicts the absolute time evolution of the base shear and overturning moment for STF, while Figure 10 shows the results for STnF. Clearly, the amplitudes of the base shear and the overturning moment are significantly smaller for the Metafoundation variant. 

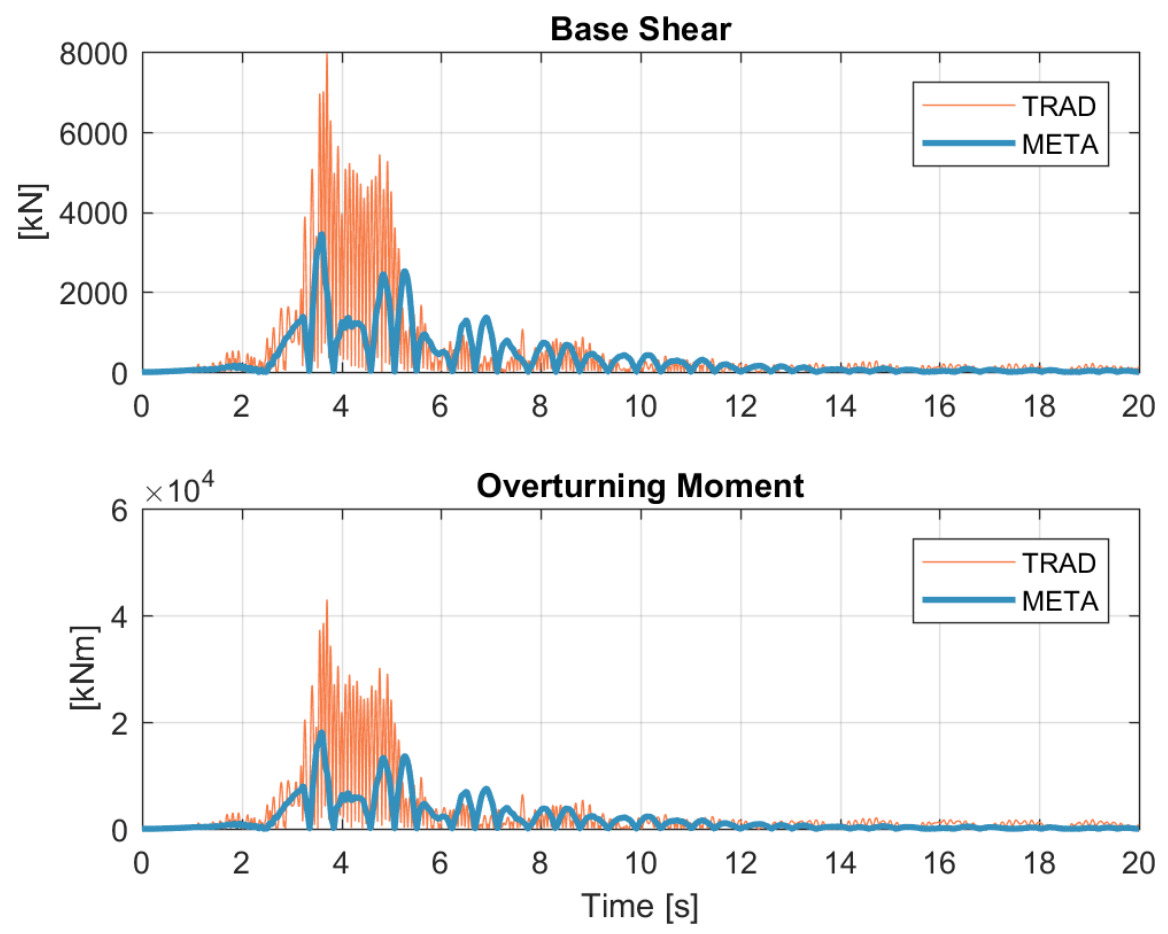

Figure 10. Absolute time evolution of the base shear and the overturning moment for STF.
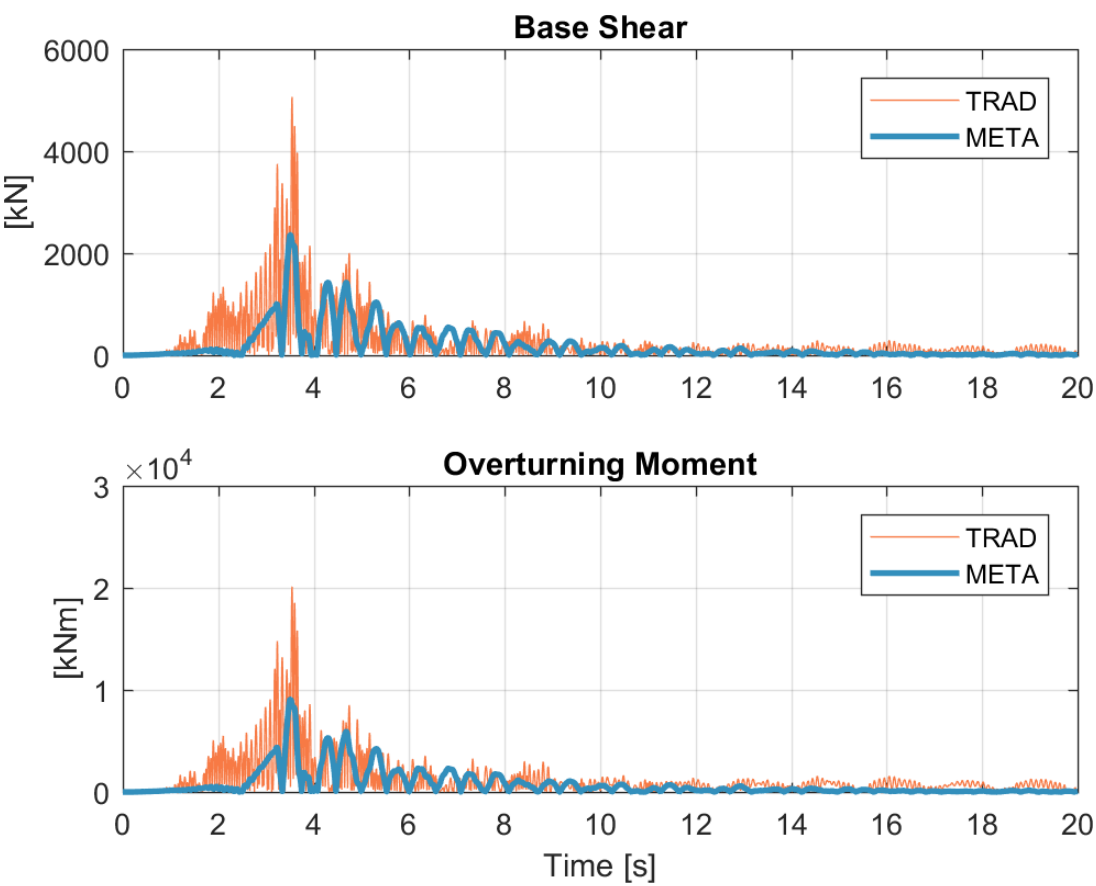

Figure 11. Absolute time evolution of the base shear and the overturning moment for $\mathrm{STnF}$

For the sake of brevity, only the maximum values of the base shear and overturning moment are presented for the rest of the ground motions ordered by PGA (Figure 11). 
Note that the time history analysis was carried out for particularly strong ground motions, in order to estimate the performance of the foundation in extreme scenarios. When comparing the maximum values of base shear and overturning moment of the two tank setups, it becomes apparent that the Metafoundation greatly attenuates the forces in the tank with respect to a traditional concrete base plate.
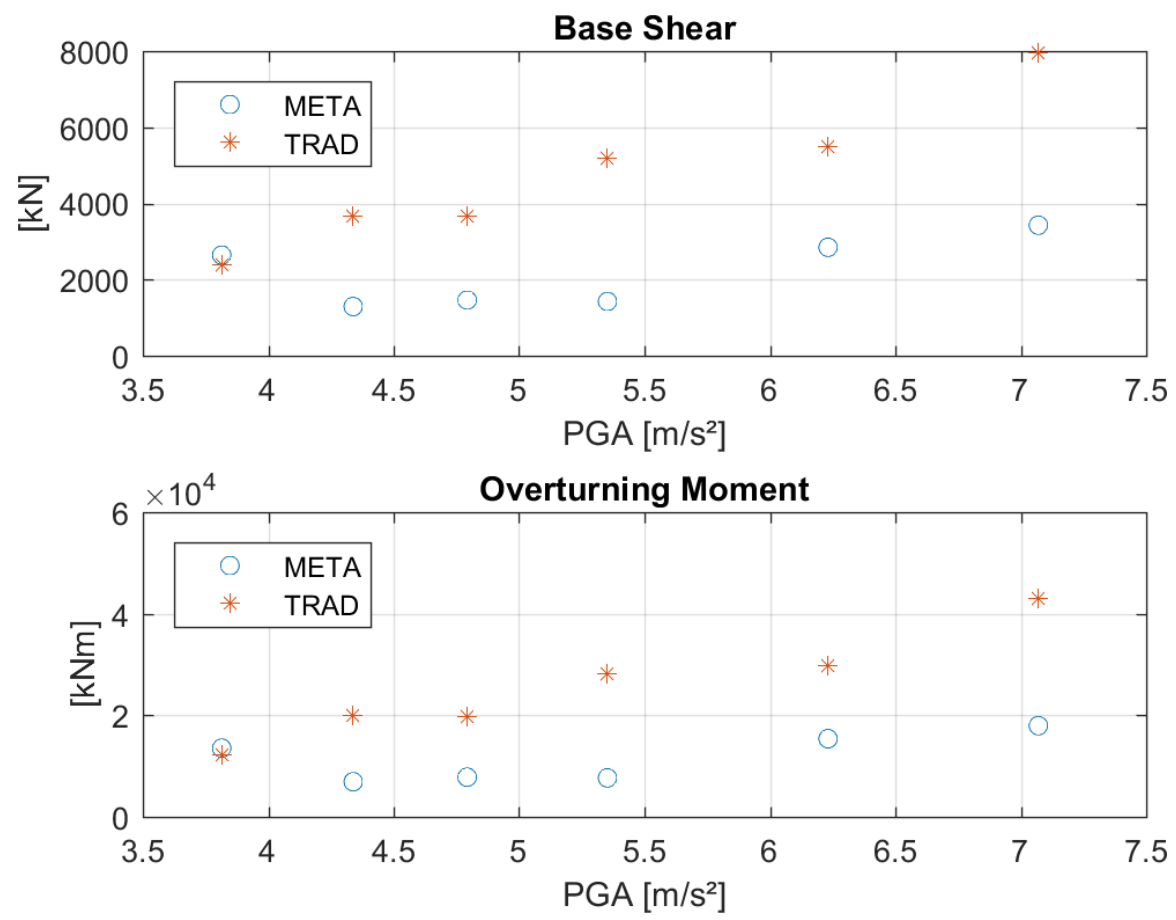

Figure 12. Maximum values of base shear and overturning moment in a full slender tank for all studied ground motions

\section{VALIDATION OF THE 1D MODEL THROUGH FE-MODELLING}

In order to numerically validate that our analytical model represents a real system, we studied an FE-model of the Metafoundation coupled with a slender tank in the frequency domain. The model was built in COMSOL Multiphysics 5.2 according to the geometry shown in Figures 2, 3, and 6 and contains the Metafoundation with resonators as lumped masses and a slender fuel storage tank. Note that in this section, the COMSOL specific 
names of the relevant FE-model elements is written in parenthesis. In particular, the columns were modelled with beam elements (Euler-Bernoulli beam), while the slabs and tank shells were modelled as shell elements (shell). The liquid inside the tank, on the other hand, was modeled as an acoustic medium with 3D elements (acpr) for the frequency domain, as this represents a good approximation when sloshing motions are neglected $[25,26]$. The interaction between the tank shell and the acoustic medium was modeled with a boundary condition of the type sound hard boundary condition (asb). Furthermore, all beam and shell elements were considered to be linear elastic and endowed with 5\% Rayleigh damping between 1 and $5 \mathrm{~Hz}$, which is equivalent to the damping used in the 1D model. The acoustic medium on the other hand was endowed with the properties of water and modelled with 3D tetrahedral elements. In sum 5313 tetrahedral elements, 2478 triangular elements, 672 edge elements, and 172 vertex elements were created with the finite element mesh. Figure 13 (left) shows the FE-model of the coupled system, while Figure 13 (right) gives an indication on the refinement of the mesh. Analogous to the procedure for the analytical model, the coupled tankfoundation system has been studied in the frequency domain and compared to the response of a tank modeled with a traditional foundation. For this purpose, an harmonic excitation of constant acceleration was applied to the bottom of the foundation, while the maximum absolute acceleration of the tank shell was recorded. When comparing the results presented in Figure 14 to Figure 8, it becomes clear that the 1D model shows , qualitatively, a very similar response with respect to the finite element model. However, since the impulsive mode according to the Malhotra procedure is supposed to model the tank response in terms of base shear rather than displacement, the amplitude of the tank 
wall in the FE simulation is not equal to the simplified 1D model. Furthermore, due to the acoustic medium, the damping of the overall system becomes much more complicated than a simple Rayleigh model could do justice. In conclusion, the 1D system is considered to be a good approximation for the evaluation of the Metafoundation and may serve as a basis for an optimization procedure. Once a feasible system has been found, more detailed FE-simulations will need to be carried out in future studies.
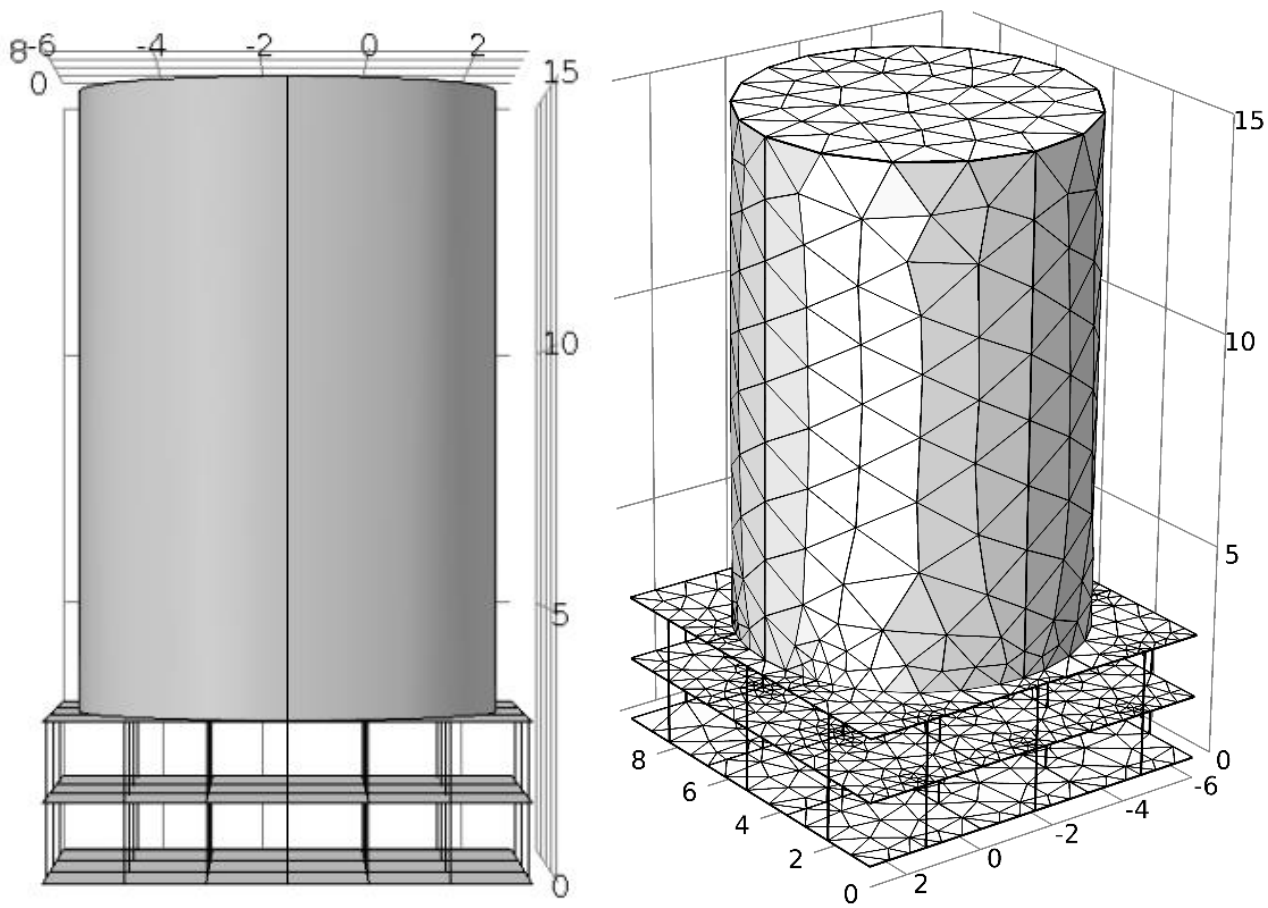

Figure 13. FE-model: (left) Side view of FE-model; (right) Isometric view of FE-model with finite element mesh. 


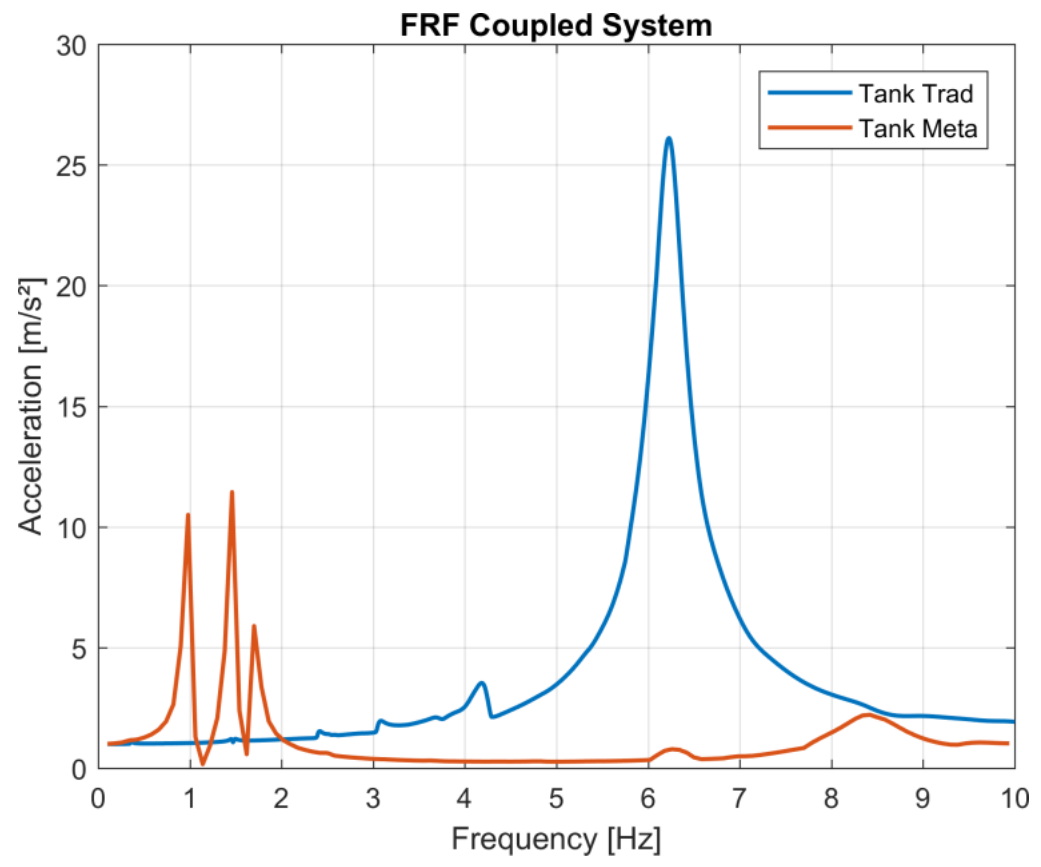

Figure 14. Frequency response function of the FE-Model of the coupled system

\section{SEISMIC PERFORMANCE OF THE COUPLED TANK-FOUNDATION-PIPELINE SYSTEM}

Pipelines are critical components of petrochemical plants and can be subjected to extreme loading conditions during earthquakes. Their potential to cause LOC events, and thus, trigger cascading effects must be treated with care. Furthermore, due to their slender nature, complicated geometry and complex boundary conditions, they are difficult to model in a realistic manner and often exert highly non-linear behavior. As a consequence, it becomes reasonable to carry out experiments for the verification of their performance. In the present work, the interaction of a tank+foundation structure coupled with a realistic piping system is investigated. This type of coupling for laboratory experiments can be achieved with a hybrid simulation (HS), where the tank and the foundation are modeled as Numerical Substructures (NS), while a piping setup in a laboratory represents the Physical Substructure (PS). The setup for the studied experiment is based on the 
theoretical work of Abbiati et al. [27], where $m$ substructures are coupled with localized Lagrange multipliers resulting in the following set of differential algebraic equations:

$$
\begin{gathered}
\boldsymbol{M}^{(l)} \ddot{\boldsymbol{u}}^{(l)}+\boldsymbol{C}^{(l)} \dot{\boldsymbol{u}}^{(l)}+\boldsymbol{K}^{(l)} \boldsymbol{u}^{(l)}=\boldsymbol{L}^{(l)^{T}} \Lambda^{(l)}-\boldsymbol{M}^{(l)} \boldsymbol{T}^{(l)} \boldsymbol{a}_{g}(\boldsymbol{t}) \\
\forall l \in\{\mathbf{1}, \ldots, \boldsymbol{m}\} \\
\boldsymbol{L}^{(l)} \dot{\boldsymbol{u}}^{(l)}+\overline{\boldsymbol{L}}^{(l)} \dot{\boldsymbol{u}}_{g}{ }^{(l)}=\mathbf{0} \\
\sum_{l=1}^{m} \overline{\boldsymbol{L}}^{(l)}{ }^{T} \Lambda^{(l)}=\mathbf{0}
\end{gathered}
$$

Here, $\boldsymbol{M}^{(l)}, \boldsymbol{C}^{(l)}$, and $\boldsymbol{K}^{(l)}$ are the mass, damping and stiffness matrix of the $l^{\text {th }}$ substructure, respectively, while $\ddot{\boldsymbol{u}}^{(l)}, \dot{\boldsymbol{u}}^{(l)}$, and $\boldsymbol{u}^{(l)}$ denote acceleration, velocity and displacement of the $l^{\text {th }}$ substructure. Moreover, the interface DoFs are collocated by the signed Boolean matrices $\boldsymbol{L}^{(l)}$ and $\overline{\boldsymbol{L}}^{(l)}$ to the substructure DoFs $\dot{\boldsymbol{u}}^{(l)}$ and the generalized interface DoFs $\dot{\boldsymbol{u}}_{\boldsymbol{g}}{ }^{(l)}$. In order to enforce compatibility between multiple substructures, localized Lagrange multiplier vectors $\boldsymbol{\Lambda}^{(l)}$ are used in (10) and (12) [28]. For more details on this procedure refer to [27]. Note that this technique can couple several numerical and/or physical substructures. Furthermore, in order to make the results relatable to the current state of the art, the Metafoundation will be compared to a system protected with concave sliding bearings (CSBs). Be aware that this system is different to the tank clamped to a traditional foundation. This change of reference system is necessary, since a tank subjected to very strong ground motions is unlikely to sustain its integrity when clamped to a concrete slab, while at the same time exhibiting very small deformations to a possible connected piping system. Therefore, a more realistic comparison was aspired by using a tank isolated with CSBs. 


\section{PHYSICAL SUBSTRUCTURE PS}

The PS consists of a piping system with its main line having a diameter of 8 in (outer diameter: $219.08 \mathrm{~mm}$, thickness: $8.18 \mathrm{~mm}$ ) and its secondary line showing a diameter of 6 in (outer diameter: $168.28 \mathrm{~mm}$, thickness: $7.11 \mathrm{~mm}$ ). Furthermore, the system comprises two elbow elements, one t-joint, and one bolted flange joint, and is based on the U.S.NRC report from 2008 [29]. Here, a large-scale shaking table test was carried out on a piping system common for the nuclear industry. As discussed in the report, masses have to be added to the structure at specified positions, in order to take valves and other components into account.

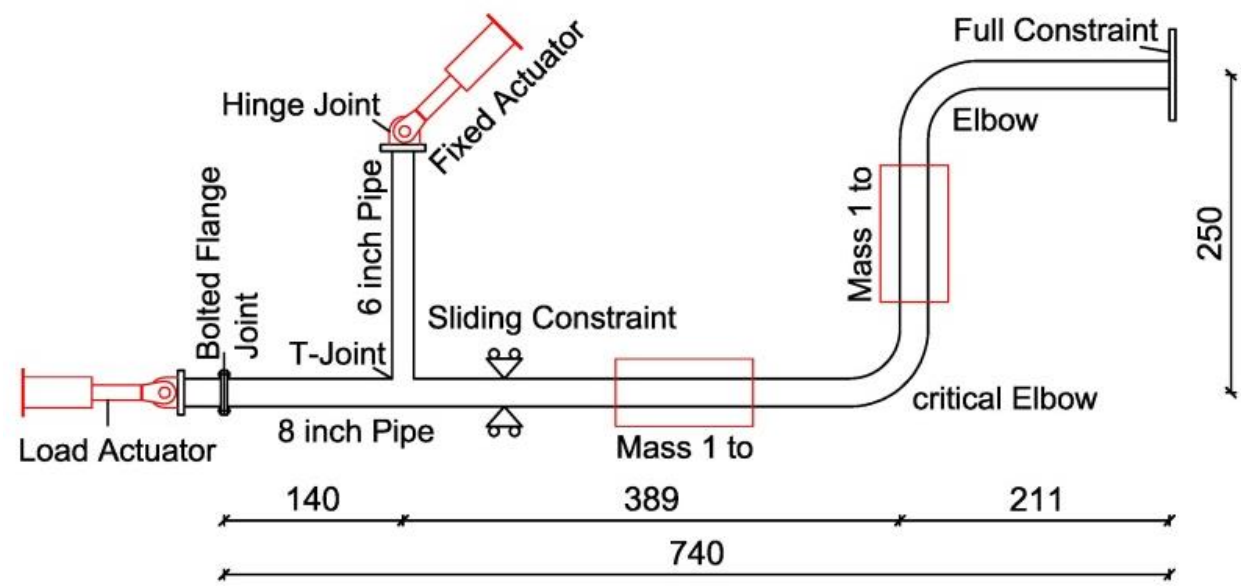

Figure 15. Schematic of the piping system (dimensions in $\mathrm{cm}$ )

The exact geometry of our system is depicted in Figure 15, while the actual specimen is represented in Figure 16. When observing these figures, it becomes clear that the real boundary conditions of the system are rather complex and that the dynamic response may be difficult to predict with an FE model. 


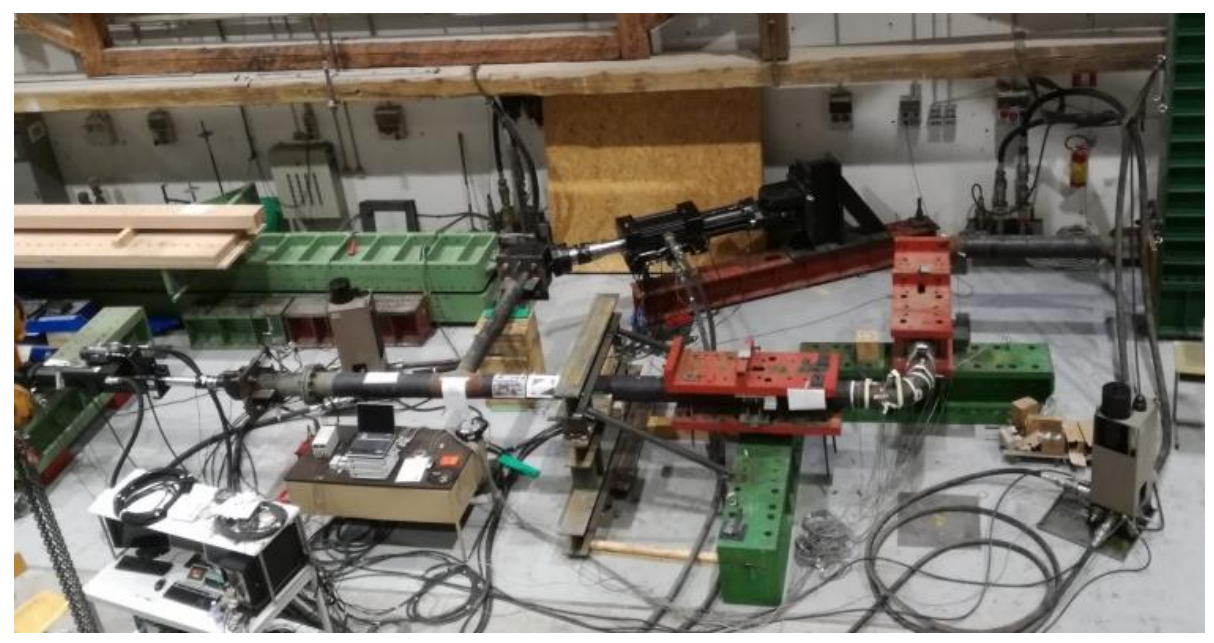

Figure 16. Experimental setup of the piping system

Additionally, the piping system was filled with pressurized water (32 bar), in order to represent a realistic scenario.

Of particular interest for the present study are the strains in the critical elbow element, since, as shown by Bursi et al. [30], elbow elements are highly vulnerable to seismic excitations and may lead to LOC events when damaged. Therefore, the strains in the critical elbow (Figure 15) are measured with strain gauges, and are considered governing for the following experimental verification. In Figure 17 the configuration of the strain gauges on the elbow is shown. Note that rose like strain gauges were applied on the inside and outside of the elbow, in order to capture the strain in radial and longitudinal direction of the pipe. 


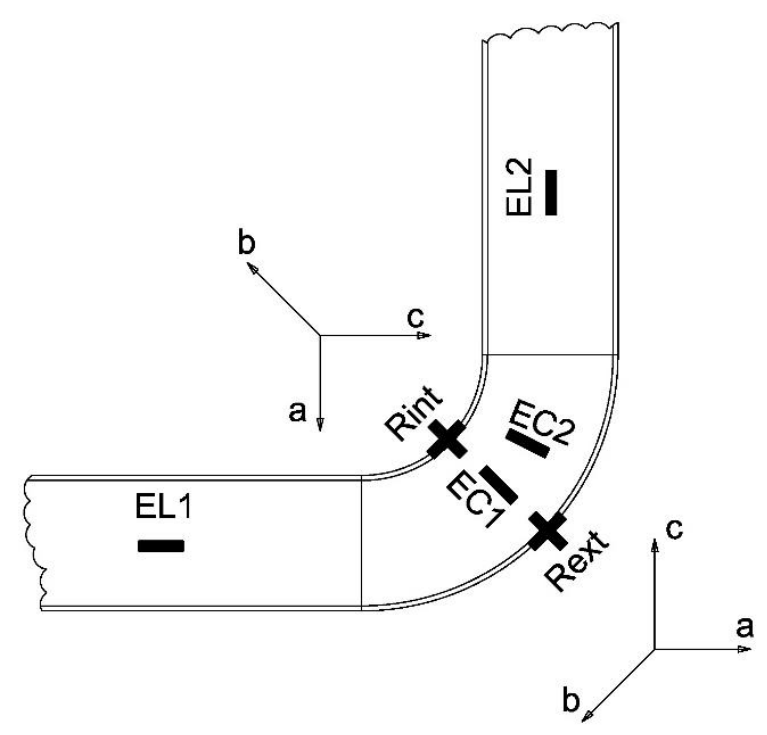

Figure 17. Configuration of strain gauges on the elbow element

The nomenclature of the strains shall be explained on the example of the REC strain gauge, where R stands for Rose, E for external gauge, and C for the vertical strain or in this case hoop strain (as indicated by the a-b-c coordinate system in the bottom right corner of Figure 17). Furthermore, the rose type strain gauges are type 3/120 RY31, while the simple gauges are type 3/350 LY41 by the company HBM Messtechnik.

\section{NUMERICAL SUBSTRUCTURE}

The NS consists of the tank and Metafoundation equal to the configuration STF, where two layers of foundation were used.

Pipes of petrochemical plants are often connected to tanks close to the tank base plate. When assuming that the relative tank deformation between ground and piping connection is very small, the pipe can be assumed to be connected to the bottom of the tank. This simplifies the numerical model, since the interface node can now be placed on the last layer of the foundation where tank, foundation and pipe coincide. Figure 18 shows a representation of the coupling of the NS with the PS. 


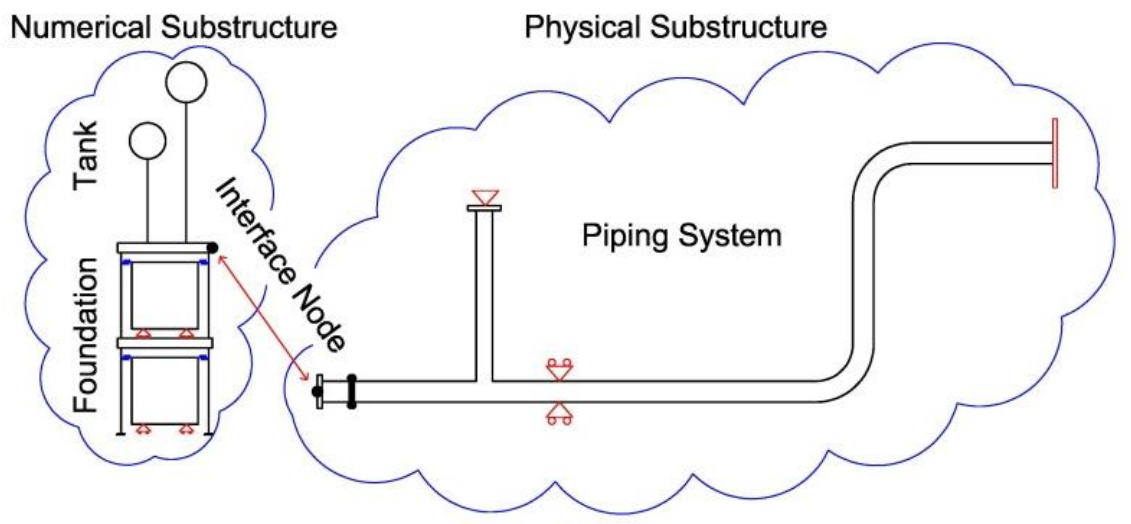

Figure 18. Coupling of the numerical and physical substructure

Furthermore, in order to draw a comparison to conventional isolation systems, an additional NS has been investigated. In particular, four CSBs (concave sliding bearings) were considered as an isolation variant for the slender tank and modeled as an alternative NS. The friction coefficient has been set to $8 \%$, while the spherical radius amounts to $5000 \mathrm{~mm}$. For a CSB, the isolation period can be calculated with $2 \pi \sqrt{2 R / g}$, where $\mathrm{R}$ is the spherical radius and $\mathrm{g}$ the gravitational constant. This amounts to an isolation period of $6.34 \mathrm{sec}$. A common approach for modeling a CSB is to use the piece-wise linear Mostaghel model as it is represented in Figure 19. This model is well described in [31], with its governing parameters $\delta_{M S T}, \alpha_{M S T}$, and $k_{M S T}$ being equal to $5 \mathrm{e}-4 \mathrm{~m}, 1.3 \mathrm{e}-3$, and 2.18e8 N/m, respectively.

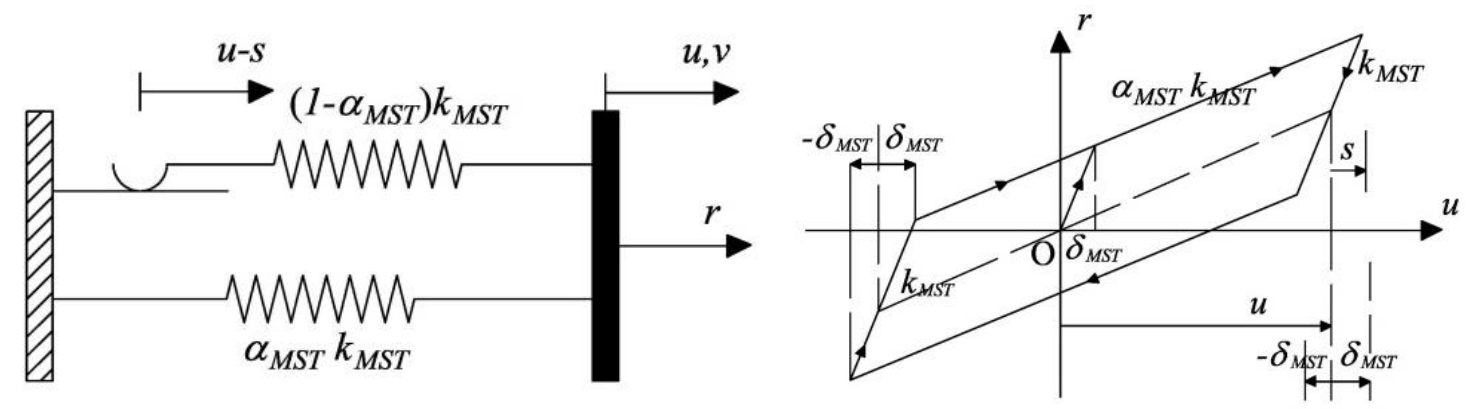

Figure 19. Generic Mostaghel model (Figure from [27]). 
All four CSB devices work in parallel and therefore can be simulated by a single device with equivalent parameters. The resulting coupling of the PS and NS is represented in Figure 20.

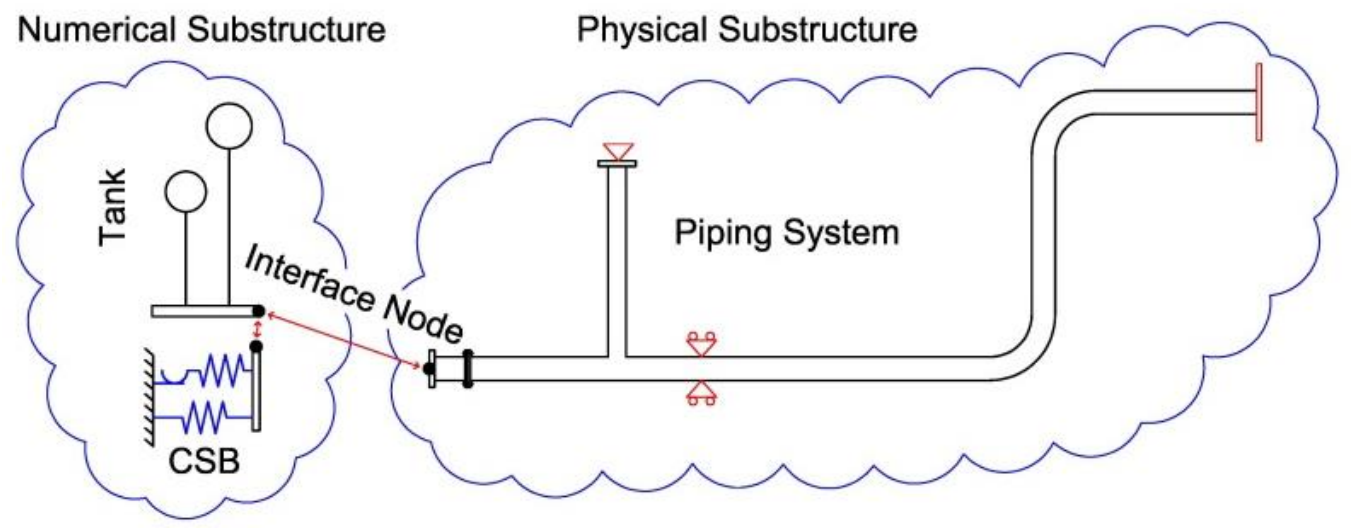

Figure 20. Numerical coupling of CSB, tank, and piping system

\section{RESULTS OF THE EXPERIMENTAL VERIFICATION}

Table 5 lists the seismic records that have been used for the experiment. In particular, two sets of Eurocode 8 [24] compatible records have been used; (i) a set of three records compatible with a site situated in Priolo Gargallo with soil type B and a return period of 475 years; (ii) 2 records from the previous set as discussed in subsection analytical results for the coupled system (return period 2475 years). Note that in Table $5 \mathrm{~T}$ denotes the expected return period of the earthquake, which is used to divide them into medium and strong ground motions. Equivalent to the earthquakes for the time history analyses, these records were extracted from the European Strong-Motion Database (ESM). 
Table 5. Seismic events for the experimental validation

\begin{tabular}{|c|c|c|c|c|c|}
\hline $\mathbf{T}$ [yrs] & Event (component) & Event ID & Mag & $\mathbf{R j b}[\mathbf{k m}]$ & PGA $\left[\mathrm{m} / \mathbf{s}^{2}\right]$ \\
\hline \multirow{3}{*}{$\frac{n}{\gamma}$} & South Iceland (Y) & 004673 & 6.5 & 15 & 4.68 \\
\hline & L'Aquila Mainshock (Y) & IT0791 & 6.3 & 9 & 3.24 \\
\hline & L'Aquila Mainshock (Y) & IT0792 & 6.3 & 5 & 6.44 \\
\hline \multirow{2}{*}{$\stackrel{n}{\stackrel{\sim}{\sim}}$} & Erincan $(\mathrm{X})$ & 000535 & 6.6 & 13 & 3.81 \\
\hline & L'Aquila Mainshock (X) & IT0789 & 6.3 & 5 & 4.34 \\
\hline
\end{tabular}

For the sake of clarity, only the results of the critical strain gauges for one of the seismic events, namely 000535, are depicted in Figure 21.
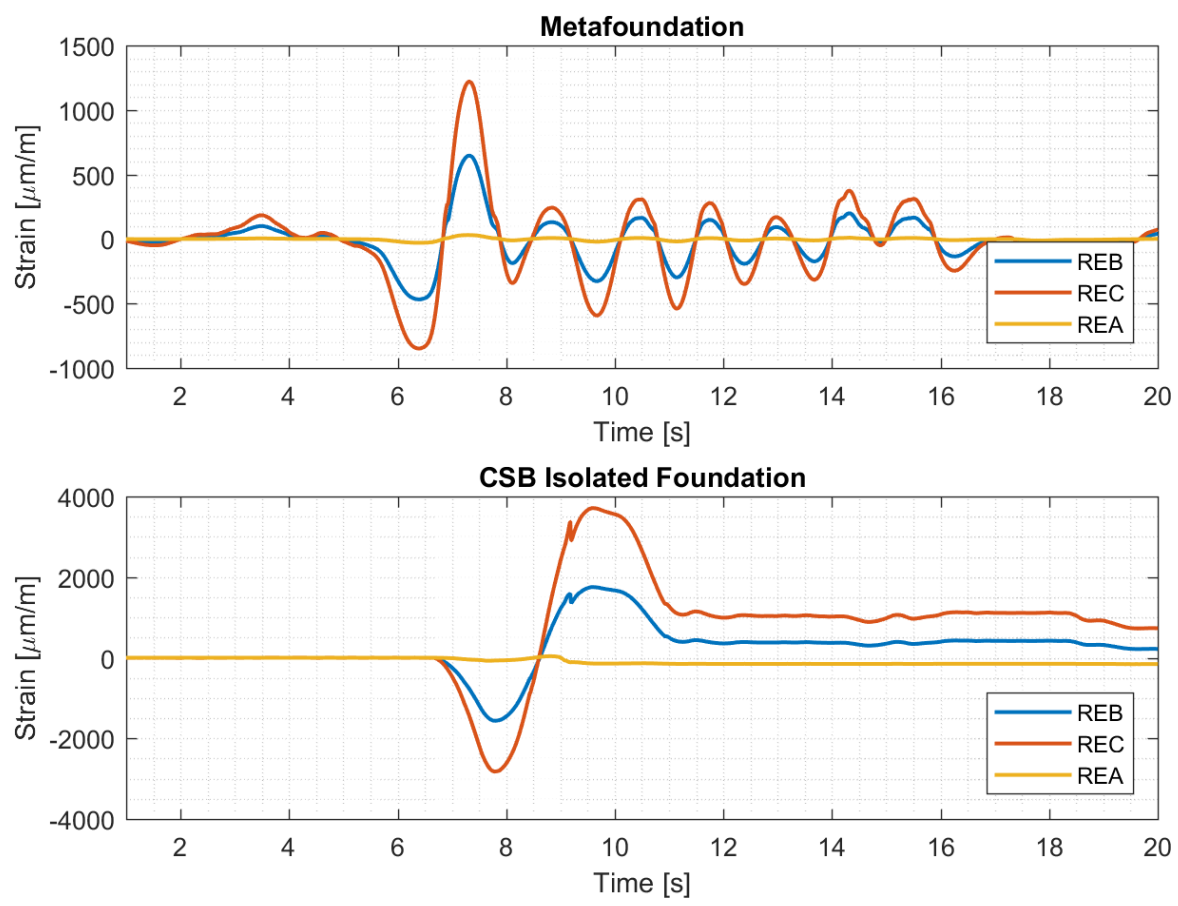

Figure 21. Strains in the critical elbow for the most sever seismic event

Since the yield strain of the piping system amounts to $2000 \mu \mathrm{m} / \mathrm{m}$, the piping system remains in the elastic range when connected to the Metafoundation, while the setup comprising the CSB array exhibits yielding in the REC strain gauge (hoop strain).

However, when comparing this result with the maximum appearing hoop strains recorded for all seismic events shown in Figure 22 (bottom), it becomes apparent that a reduction of hoop strain cannot be assumed for any given earthquake. On average, the 
Metafoundation reduces the hoop strain by $37 \%$, while the maximal reduction, obtained for event 000535 amounts to $67 \%$. From the high dispersion of the results, it becomes clear that the average reduction is heavily influence by the extreme event. This excessive strain measured for the CSB, is due to the low post yielding stiffness of the non-linear system, which makes it difficult to predict what earthquakes may trigger yielding in the pipeline. However, since the Metafoundation is a linear system, also it's response scales linearly with the excitation and therefore, such extreme events are less likely. Moreover, the CSB setup shows a much better performance in terms of base shear, with an average decrease of $73 \%$ and a maximal reduction of $85 \%$ with respect to the Metafoundation. It is worth noting however, that a CSB is a highly specialized device that has been optimized over many years and requires regular maintenance and inspection. From the obtained results, we deduce that the developed foundation is not a better solution than a CSB array, but that it clearly shows some positive wave attenuation behavior and that with more research and optimization, it may provide a viable alternative. Additionally, for a more reliable performance of the system, it may be necessary to take the piping system into account when tuning the foundation. This, on the other hand, is not within the scope of the present work. 

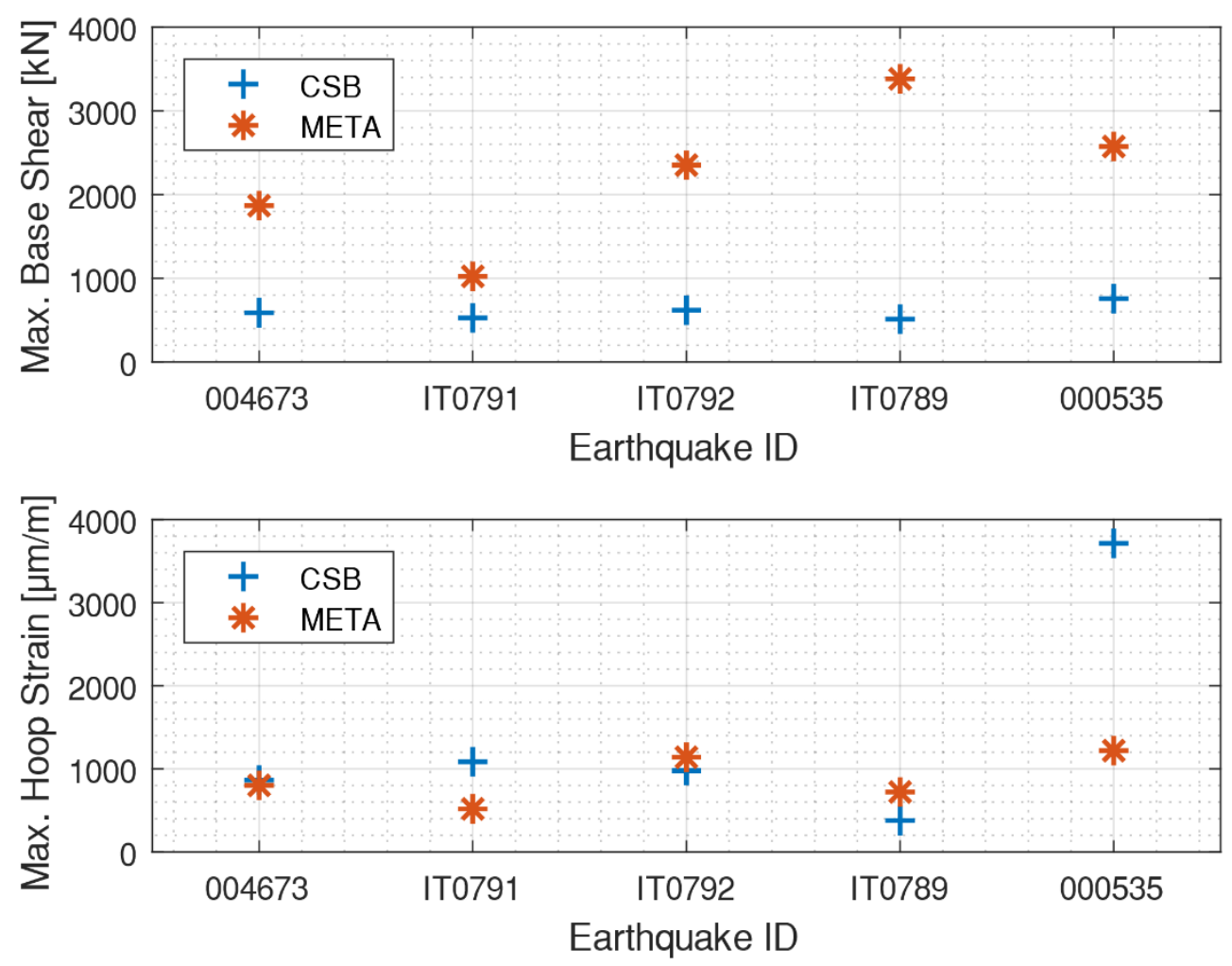

Figure 22. Experimental results: (top) Base shear of the tank; (bottom) maximal hoop strain in the elbow (REC).

\section{CONCLUSION}

The proposed Metafoundation represents a novel type of seismic shield and has been designed to protect fuel storage tanks from ground motions. Through analyses in the frequency and time domain, we have demonstrated the effectiveness of the foundation at attenuating seismic effects. More precisely, a slender fuel storage tank may profit greatly from the proposed foundation in terms of attenuation of base shear and overturning moment with respect to a traditional concrete foundation. Additionally, the conducted laboratory tests shed light on the interaction of the Metafoundation with the complete coupled structure (tank + foundation + pipeline) and made it comparable to standard isolation devices. The measured elbow strains show no plastification for the system 
coupled with the Metafoundation, while the configuration including the CSB array exeeds the critical yield strain for one of the investigated ground motions. However, since some seismic events showed a higher demand in the elbow when coupled to the Metafoundation, a clear advantage of the Metafoundation cannot be concluded yet. In future studies the tuning of the foundation could potentially be expanded to the complete coupled system and, consecutively, reduce stresses in a connected piping system more reliably. Besides the attenuation of horizontal excitations, the foundation may offer interesting properties regarding soil-structure interaction damping. 


\section{ACKNOWLEDGMENT}

This project has received funding from the European Union's Horizon 2020 research and innovation program under the Marie Skłodowska-Curie grant agreement no. 721816 for the first author and the SERA grant agreement no. 730900 for the remaining authors.

\section{FUNDING}

European Union, through the XP-Resilience Project (No 721816). European Union, through the SERA Project (No 730900).

\section{REFERENCES}

[1] Cruz, A. M., Steinberg, L. J., 2006, “Emerging Issues for Natech Disaster Risk Management in Europe", Journal of Risk Research, 9(5), 483-501. DOI: $10.1080 / 13669870600717657$

[2] Steinberg, L. J., Sengul, H., Cruz, A. M., 2008, "Natech risk and management: an assessment of the state of the art", Natural Hazards, 46(2), 143-152. DOI: $10.1007 / \mathrm{s} 11069-007-9205-3$

[3] Cozzani, V., Antonioni, G., Landucci, G., Tugnoli, A., Bonvicini, S., Spadoni, G., 2014, "Quantitative assessment of domino and NaTech scenarios in complex industrial areas", Journal of Loss Prevention in the Process Industries, 28, 10-22. DOI: $10.1016 /$ j.jlp.2013.07.009

[4] Barka, A., (1999). “The 17 August 1999 Izmit Earthquake”. Science 285(5435), 1858-1859. DOI: $10.1126 /$ science.285.5435.1858

[5] Nakashima, M., Lavan, O., Kurata, M., Luo, Y., (2014), "Earthquake Engineering Research Needs in Light of Lessons Learned from the 2011 Tohoku Earthquake", Earthquake Engineering and Engineering Vibration, 13, 141-149. DOI: 10.1007/s11803-014-0244-y

[6] Kelley, J. M., Konstantinidis, 2011, Mechanics of rubber bearings for seismic and vibration isolation, John Wiley \& Sons, Ltd, ISBN: 9781119994015

[7] Mokha, A., Constantinou, C., Reinhorn, A. M., Zayas, V. A., 1991, "Experimental Study of Friction-Pendulum Isolation System", Journal of Structural Engineering, 117(4), 1201-2117. DOI: 10.1061/(ASCE)0733-9445(1991)117:4(1201) 
[8] Jadhav, M. B., Jangid, R. S., 2004, "Response of base-isolated liquid storage tanks", Shock and Vibration 11, 33-45. DOI:10.12989/sem.2006.23.6.615

[9] Solymar, L., Shamonina, E., 2009, Waves in Metamaterials, Oxford University Press, Oxford, UK, Chap. 2. ISBN: 978-0-19-921533-1

[10] Sigalas, M., Kushwaha, M. S., Economou, E. N., Kafesaki, M., Psarobas, I. E., Steurer, W., 2009. "Classical vibration modes in phononic lattices: theory and experiment.", Zeitschrift für Kristallographie - Crystalline Materials 220(9-10). DOI:10.1524/zkri.2005.220.9-10.765

[11] Cheng, Z., Shi, Z. F., 2017. "Composite periodic foundation and its application for seismic isolation". Earthquake Engineering and Structural Dynamics, 1-20. DOI: 10.1002/eqe.2999

[12] Cheng, Z., and Zhifei, S., 2013. "Novel composite periodic structures with attenuation zones." Engineering Structures 56, 1271-1282. DOI: 10.1016/j.engstruct.2013.07.003

[13] Gaofeng, J., and Zhifei, S., 2010. "A new seismic isolation system and its feasibility study." Earthquake Engineering and Engineering Vibration 9, 75-82. DOI: $10.1007 / \mathrm{s} 11803-010-8159-8$

[14] Ha, Y.-K., Kim, J.-E., Park, I.-W., and Lee, H. Y., 2002. "Propagation of water waves through finite periodic arrays of vertical cylinders.” Applied Physics Letters 81(7). DOI: $10.1063 / 1.1499520$

[15] Yan, Y., Laskar, A., Cheng, Z., Menq, F., and Tang, Y., 2014. "Seismic isolation of two dimensional periodic foundations." Journal of Applied Physics 116(044908). DOI: $10.1063 / 1.4891837$

[16] Bursi, O. S., Abbiati, G.,Reza, Md S., 2014, "A novel testing approach for piping systems of industrial plants", Smart Structures and Systems 14(6). DOI: http://dx.doi.org/10.12989/sss.2014.14.6.000

[17] Bursi, O. S., Reza, Md S., Abbiati, G., Paolacci, F., 2015, "Performance-based earthquake evaluation of a full-scale petrochemical piping system", Journal of Loss Prevention in the Process Industries 33, 10-22. DOI: http://dx.doi.org/10.1016/j.jlp.2014.11.004

[18] EN 1992-1-1. (2003). Eurocode 2: Design of Concrete Structures - Part 1-1: General Rules and Rules for Buildings. CEN: Bruxelles.

[19] Malhotra, K. P., Wenk, T., and Wieland, M., 2000. "Simple procedure for seismic analysis of liquid-storage tanks.”, Struct. Eng. Int. 10, 197-201. DOI:10.2749/101686600780481509

[20] Belakroum, R., Kadja, M., Mai, T., and Maalouf, C., 2010., “An efficient passive technique for reducing sloshing in rectangular tanks partially filled with liquid.", Mech. Res. Commun. 37, 341-349. DOI:10.1016/j.mechrescom.2010.02.003 
[21] Maleki, A., Ziyaeifar, M., 2008, "Sloshing damping in cylindrical liquid storage tanks with baffles", Journal of Sound and Vibration 311, 372-385, DOI:10.1016/j.jsv.2007.09.031

[22] Phani, A. S., Woodhouse, J., and Fleck, N. A., 2006, "Wave propagation in twodimensional periodic lattices", J. Acoust. Soc. Am. 119, 1995-2005. DOI:10.1121/1.2179748

[23] Huang, H. H., Sun, C. T., and Huang, G. L., 2009; "On the negative effective mass density in acoustic metamaterials.”, Int. J. Eng. Sci. 47, 610-617. DOI:10.1016/j.ijengsci.2008.12.007

[24] EN 1998-1-1. (2005). Eurocode 8: Design of structures for earthquake resistance Part 1: General rules, seismic actions and rules for buildings. CEN: Bruxelles.

[25] Carta, G., Movchan, A. B., Argani, L. P., and Bursi, O. S., 2016, "Quasi-periodicity and multi-scale resonators for the reduction of seismic vibrations in fluid-solid systems", International Journal of Engineering Science 109, 216-239. DOI:10.1016/ijengsci.2016.09.010

[26] Ding, W. P., and Chen, H. L., 2001, “A symmetrical finite element model for structure-acoustic coupling analysis of an elastic, thin-walled cavity", Journal of Sound and Vibration 243(3), 547-559. https://doi.org/10.1006/jsvi.2000.3478

[27] Abbiati, G., La Salandra, V., Bursi, O. S., Caracoglia, L., 2017, “A composite experimental dynamic substructuring method based on partitioned algorithms and localized Lagrange multipliers", Mechanical Systems and Signal Processing 100, 85-112. DOI: 10.1016/j.ymssp.2017.07.020

[28] Park, K. C., Felippa, C. A., Gumaste, U. A., 2000," A localized version of the method of Lagrange multipliers and its applications", Computational Mechanics 24(5), 476-490. DOI: https://doi.org/10.1007/s004660050007

[29] U.S.NRC, 2008, "Seismic Analysis of Large-Scale Piping Systems for the JNESNUPEC Ultimate Strength Piping Test Program", Office of Nuclear Regulatory Research.

[30] Bursi, O. S., Di Filippo, R., La Salandra, V., Pedot., M., Reza, S., 2017, "Probabilistic seismic analysis of an LNG subplant", Journal of Loss Prevention in the Process Industries, in press. DOI:10.1016/j.jlp.2017.10.009

[31] Mostaghel, N., 1999, “Analytical Description of Pinching, Degrading Hysteretic Systems", Journal of Engineering Mechanics, 125(2), 216-224.

DOI:10.1061/(ASCE)0733-9399 